\title{
PERFORMANCE EVALUATION OF MASS TRANSFER-BASED METHOD USING GLOBAL PERFORMANCE INDEX IN SEMI- ARID REGION, SAUDI ARABIA
}

\author{
ISLAM, S. ${ }^{1 *}-$ ABDULlaH, R. A. B. ${ }^{1}-$ AlgahtANI, A. ${ }^{2,3}-$ IRSHAD, K. $^{4}-$ HIROL, H. ${ }^{1}$ \\ ${ }^{I}$ Department of Civil Engineering, University Teknologi Malaysia, P.O. Box 81310, Johor \\ Bahru, Johor, Malaysia \\ ${ }^{2}$ Mechanical Engineering Department, College of Engineering, King Khalid University, Abha \\ 61413, Asir, Kingdom of Saudi Arabia \\ ${ }^{3}$ Research Centre for Advanced Materials Science (RCAMS), King Khalid University, P.O. Box \\ 9004, Abha 61413, Asir, Kingdom of Saudi Arabia \\ ${ }^{4}$ Center of Research Excellence in Renewable Energy (CoRERE), King Fahd University of \\ Petroleum \& Minerals, Dhahran, Saudi Arabia \\ *Corresponding author \\ e-mail: isaiful2@graduate.utm.my; phone: +966-59-521-9933; fax: +966-17-241-8816
}

(Received $4^{\text {th }}$ Apr 2019; accepted $11^{\text {th }}$ Jul 2019)

\begin{abstract}
The main aim of this research work is to assess the performance of the various mass transferbased method with respect to standard FAO56-PM. Daily meteorological data from 1979 to 2018 has been used to compute reference evapotranspiration (ETo). The climatic data from 1979 to 2006 were used for the development of the calibrated equations and data from 2007 to 2018 were applied for validation purpose. The evaluated, calibrated and further validation of calibrated models were compared using statistical tools in order to ranked the models effectiveness using Global Performance Indicator (GPI) where higher GPI value shows better model. The models were then arranged using GPI and it was found that proposed model resulted with best GPI value of 5.02, 2.85 and 5.19 during evaluation, calibration and validation respectively followed by Albrecht model. The results of this study could be used by the water management system, crop cultivators, crop advisors, researchers from research centres. Moreover, it is beneficial for the decision maker in the vast field of agriculture, hydrology and environment. The calibration and validation of different ETo equations tend to increase their performance. Thus, the validated evapotranspiration model that used less climatic parameters can predict the ETo condition accurately for Asir region.
\end{abstract}

Keywords: water management, calibration, validation, semi-arid condition, reference evapotranspiration model, mass transfer equation

\section{Introduction}

Precise evaluation of reference evapotranspiration (ETo) plays a vital role for water resource management, efficient irrigation management, crop production, environmental assessment (Estevez et al., 2016). The reference evapotranspiration can be measured directly by lysimeter (Xu et al., 2013). However, measurements by lysimeter proved to be tedious work (Irmak et al., 2003). Consequently, Food and Agriculture Organization of the United Nations (FAO) recommends the standard Penman-Monteith FAO-56 PM, which was acknowledged in various parts of the world (Allen et al., 1998). Notwithstanding the aforementioned technique have shortcoming under certain unique conditions (Widmoser, 2009); however, it is still considered the standard technique for computing evapotranspiration for a reference surface (Xystrakis and Matzarakis, 2010; 
Tabari et al., 2013), i.e., well-watered, actively growing grass of a height of $0.12 \mathrm{~m}$ with an albedo of 0.23 that uniformly covers the area and has a surface resistance of $70 \mathrm{~s} / \mathrm{m}$ (Allen et al., 1998). The only shortcoming in FAO56-PM is that it requires various climatic data which are not easily available or measured. Hence keeping this shortcoming in mind many researchers have developed reference evapotranspiration equation which requires lesser input parameters that are categorized as mass transfer-, radiation-, temperature-, and pan evaporation-based methods (Sentelhas et al., 2010). However, such empirical equations need to be rectified by calibration against lysimetric or standard FAO56-PM technique at different regions. The researchers have performed various studies for simplified evapotranspiration equations against the FAO56-PM technique around the world, including Iran (Tabari et al., 2013), Southern Greece (Xystrakis and Matzarakis, 2010), Canada (Sentelhas et al., 2010), Tunisia (Jabloun and Sahli, 2008), Bulgaria (Popova et al., 2006), the Syria, the USA, Netherlands, the Philippines and Spain (Stockle et al., 2004). The past studies in saudi Arabia were basically assessed different ETo models against the FAO-56 Penman Monteith model based on the Central and Eastern region of Saudi Arabia (Salih and Sendil, 1984; AboGhobar and Mohammad, 1995; Al-Omran et al., 2004; Elnesr et al., 2010; Islam et al.,2019). However very less study have been done in regards with evaluation calibration and validation of mass transfer equation. The mass transfer-based models are based on the principle of Dalton's law and employ eddy motion transfer of water vapor from an evaporating surface to the atmosphere (Singh and $\mathrm{Xu}, 2002$; Tabari et al., 2013), the performance accuracy of these models reduces if aerodynamic effects have lower value as discussed by (Kiefer et al., 2017). These results provide significantly accurate result in many cases (Jensen, 1974). However, air temperature and wind speed have been measured at inconsistent heights, resulting different equations with similar or identical structure. So, the outcome resulting from input climatic condition varies from one location and or height to another and will be difficult to do with certainty (Helfrich, 1982). The mass transfer-based equation as compared to Standard FAO56-PM model have rarely been used in Southern region of Saudi Arabia. Hence, it is utmost important to carry out research based on evaluating the performance of various mass transfer reference evapotranspiration models to determine the best, or a relatively appropriate model for estimating the ETo in Semi-arid region. This can aid in recognizing the suitable method that can be used as an alternative equation to standard FAO56-PM method. The finding of the research work is helpful in reducing the error during the evapotranspiration computation. Moreover, the best-evaluated model equation the for evapotranspiration could assist in computing the evapotranspiration in future in the field of water management system, climate change studies, irrigation and water resource planning.

\section{Study area}

\section{Site description}

The research work deals with Abha mountainous region of Aseer province, Kingdom of Saudi Arabia having an area of $370 \mathrm{~km}^{2}$ located between the latitude of $18^{\circ} 10^{\prime} 12.39^{\prime \prime} \mathrm{N}$ and $18^{\circ} 23^{\prime} 33.05^{\prime \prime} \mathrm{N}$ and longitude of $42^{\circ} 21^{\prime} 41.58^{\prime \prime} \mathrm{E}$ and $42^{\circ} 39^{\prime} 36.09^{\prime \prime} \mathrm{E}$ as shown in Figure 1. The zone is prone to heavy rainfall as compared to other parts of Saudi Arabia. The elevation varies from 1951 to $2991 \mathrm{~m}(\mathrm{msl})$ with average precipitation of $355 \mathrm{~mm}$ which mainly occurs between June and October. 


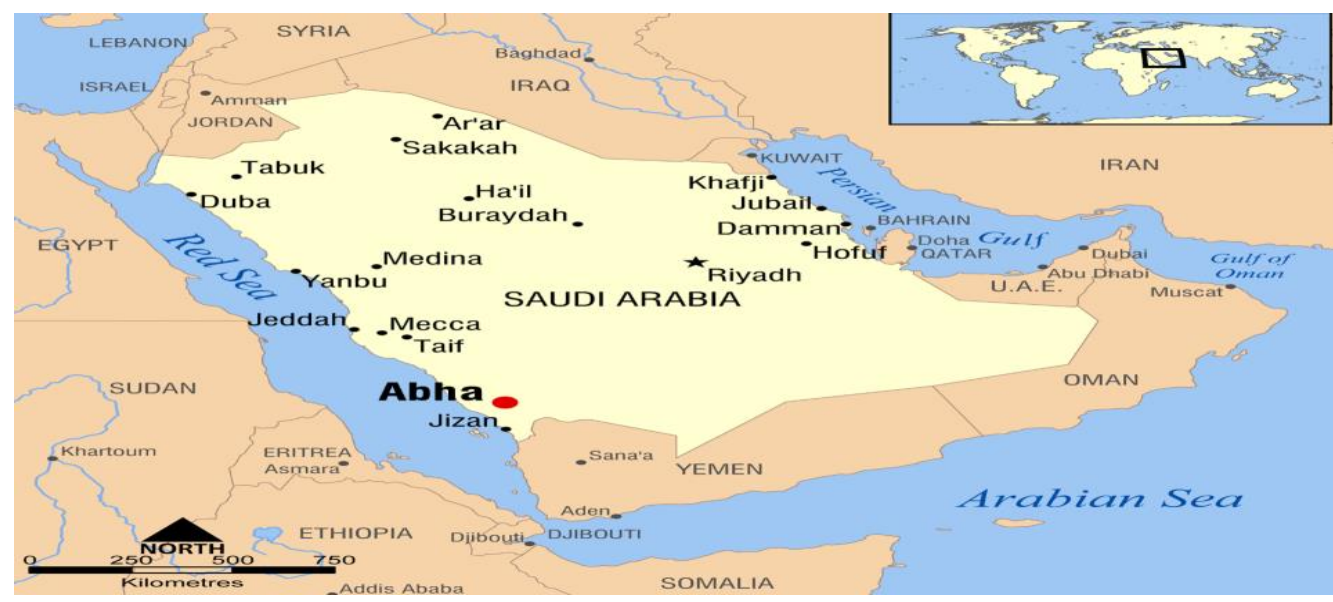

Figure 1. Location map of Abha Asir region, Kingdom of Saudi Arabia

\section{Data availibility}

In this research work, weather parameters were collected from Abha meteorological weather station for the period between 1979 and 2018 which includes wind velocity, mean temperature, maximum and minimum temperature, mean relative humidity and solar radiation as well. The data collected were checked (Arnold and Allen, 1996). The weather data are shown in Table 1.

Table 1. Characteristics of Abha weather parameters during the study period

\begin{tabular}{c|c|c|c|c|c}
\hline & $\begin{array}{c}\text { Max temp } \\
\left({ }^{\circ} \mathbf{C}\right)\end{array}$ & $\begin{array}{c}\text { Min temp } \\
\left({ }^{\circ} \mathbf{C}\right)\end{array}$ & $\begin{array}{c}\text { Mean temp } \\
\left({ }^{\circ} \mathbf{C}\right)\end{array}$ & $\begin{array}{c}\text { Wind velocity } \\
(\mathbf{m} / \mathbf{s})\end{array}$ & $\begin{array}{c}\text { Humidity } \\
(\mathbf{\%})\end{array}$ \\
\hline Max & 35.1 & 21.4 & 25.1 & 5.23 & 88 \\
Min & 20.3 & -0.4 & 11.9 & 0.75 & 14 \\
Mean & 28.60 & 9.12 & 18.76 & 2.36 & 54.77 \\
StDev & 3.68 & 4.41 & 3.73 & 0.64 & 12.96 \\
Kurtosis & -1.18 & -1.05 & -1.39 & 2.57 & -0.66 \\
Skewness & -0.17 & -0.128 & -0.06 & 1.14 & 0.043 \\
\hline
\end{tabular}

\section{Methodology}

In this research work ETo were estimated by nine mass transfer reference evapotranspiration model and one proposed model based on available climatic data. Moreover, the reference ETo values were estimated using standardized FAO56-PM. The values evaluated from different mass transfer based equations were compared with the reference value obtained from FAO56-PM for the period between 1979 and 2018. Further, all ten equations were calibrated for the period between 1979 and 2006 then validation of calibrated equation for the period between 2007 and 2018 with respect to FAO56-PM model. The performance of equations was evaluated by utilizing ten statistical finally based on evaluation criteria the global performance index has been computed and the ranking were done in order to get most promising model which can be used alternative to FAO56-PM model. The flowchart (Fig. 2) described the stepwise procedure to compute most promising model among nine model to be used as alternate of FAO56-PM model. 


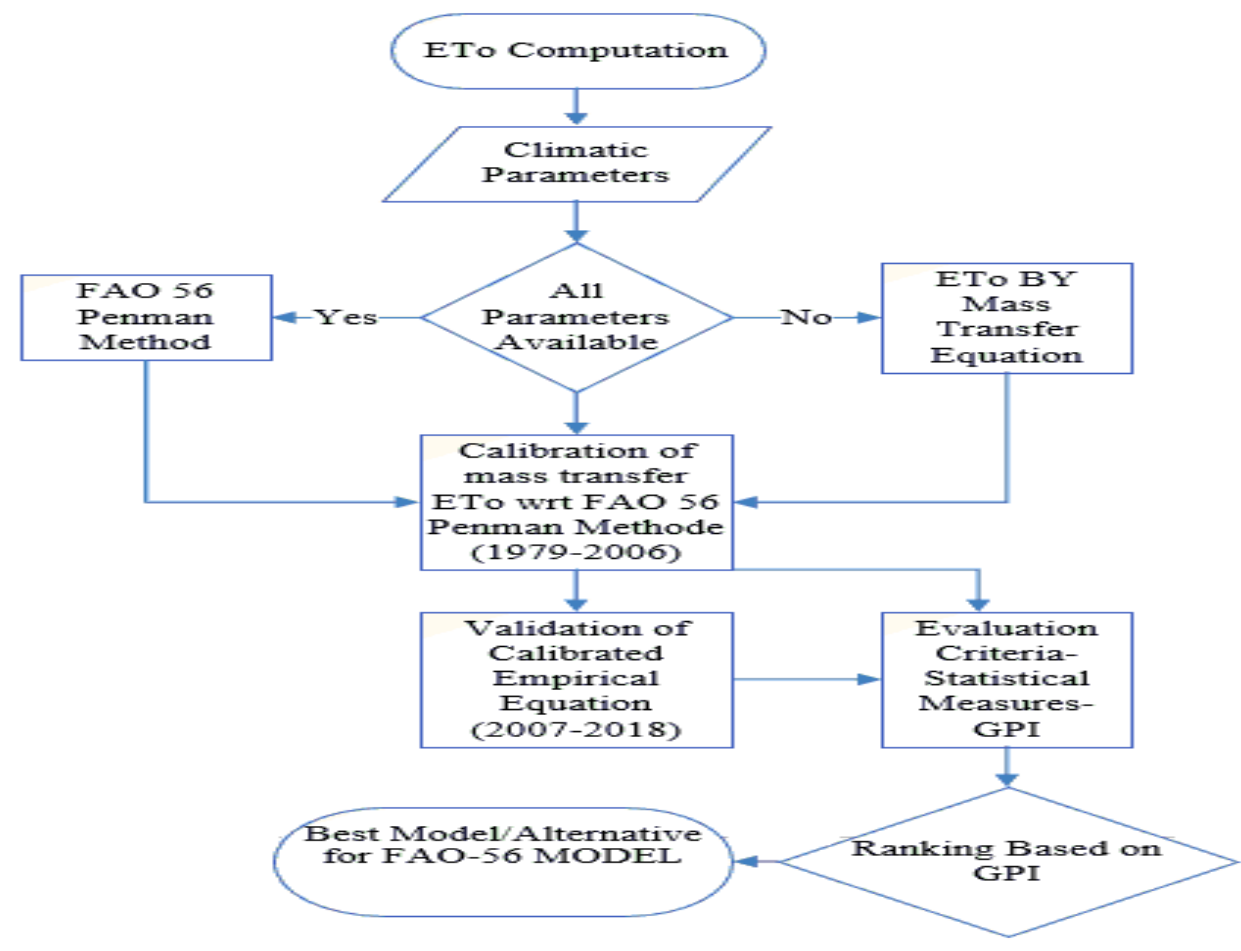

Figure 2. Flowchart showing stepwise computation of ETo

\section{Reference evapotranspiration (ETo) model}

This study work aims to analyze trends of the monthly ETo calculated by the Standard FAO56-PM model as given by equation 1 in the Asir region, Kingdom of Saudi Arabia. However, the use of the FAO56-PM is restrained due to limited climatic input parameters; hence, the alternative solution is to use various mass transfer models. In this research work nine-mass transfer and one proposed alternative method for estimating ETo have been chosen for this study. The selection of methods was based on their wide acceptance, simple calculation procedure and applicability in present conditions. The models are described as equations $2-10$.

FAO Penman-Monteith (Allen et al., 1998)

$$
E T o=\frac{0.408 \times \Delta \times(R n-G)+\gamma \times\left(\frac{900}{T+273}\right) \times u_{2} \times\left(e_{s}-e_{a}\right)}{\Delta+\gamma \times\left(1+0.34 u_{2}\right)}
$$

Mass transfer based ETo model

Dalton (1802)

$$
\text { ETo }=\left(0.3648+0.07223 u_{2}\right) \times\left(e_{s}-e_{a}\right)
$$

Trabert (1896)

$$
\text { ETo }=0.408 \times 0.3075 \times \sqrt{u_{2}} \times\left(e_{s}-e_{a}\right)
$$

Meyer (1926)

$$
\text { ETo }=\left(0.375+0.05026 u_{2}\right) \times\left(e_{s}-e_{a}\right)
$$


Rohwer (1931)

$$
E T o=0.44\left(1+0.27 u_{2}\right) \times\left(e_{s}-e_{a}\right)
$$

Penman (1948)

$$
E T o=0.35 \times\left(1+0.24 u_{2}\right) \times\left(e_{s}-e_{a}\right)
$$

Albrecht (1950)

$$
E T o=\left(0.1005+0.297 u_{2}\right) \times\left(e_{s}-e_{a}\right)
$$

Brockamp (1963)

$$
E T o=\left(0.543 u_{2}^{0.456}\right) \times\left(e_{s}-e_{a}\right)
$$

WMO (1966)

$$
\text { ETo }=\left(0.1298+0.0934 u_{2}\right) \times\left(e_{s}-e_{a}\right)
$$

Mahringer (1970)

$$
\text { ETo }=0.15072 \times \sqrt{3.6 u_{2}} \times\left(e_{s}-e_{a}\right)
$$

where ETo $=$ reference evapotranspiration $\left(\mathrm{mm} \mathrm{day}^{-1}\right) ; \mathrm{Rn}=$ net radiation at the crop surface $\left(\mathrm{MJm}^{-2}\right.$ day $\left.^{-1}\right) ; \mathrm{G}=$ soil heat flux density $\left(\mathrm{MJm}^{-2}\right.$ day $\left.{ }^{-1}\right)$ ) that is taken as zero for daily ETo estimation; $\mathrm{u}_{2}=$ wind speed at $2 \mathrm{~m}$ height $\left(\mathrm{m} \mathrm{s}^{-1}\right)$; $\mathrm{e}_{\mathrm{s}}=$ saturation vapor pressure $(\mathrm{kPa}) ; \mathrm{e}_{\mathrm{a}}=$ actual vapor pressure $(\mathrm{kPa}) ; \mathrm{T}=$ temperature at $2 \mathrm{~m}$ height $\left({ }^{\circ} \mathrm{C}\right)$; $\left(\mathrm{e}_{\mathrm{s}}-\mathrm{e}_{\mathrm{a}}\right)=$ vapor pressure deficit $(\mathrm{kPa}) ; \Delta=$ slope of vapor pressure curve $\left(\mathrm{kPa}^{\circ} \mathrm{C}^{-1}\right)$; and $\gamma=$ psychrometric constant $\quad\left(\mathrm{kPa} \quad{ }^{\circ} \mathrm{C}^{-1}\right) ; \quad \mathrm{T}_{\max }=$ Maximum Temperature $\quad\left({ }^{\circ} \mathrm{C}\right)$; $\mathrm{T}_{\min }=$ Minimum Temperature $\left({ }^{\circ} \mathrm{C}\right) ; \mathrm{T}_{\text {mean }}=$ Mean Temperature $\left({ }^{\circ} \mathrm{C}\right) ; \mathrm{RH}_{\text {mean }}=$ Mean Relative Humidity (\%); $\mathrm{RH}_{\max }=$ Maximum Relative Humidity (\%); $\mathrm{RH}_{\min }=$ Minimum Relative Humidity (\%)

\section{Model development and validation}

The fact that leads to model development in study area is that the previously established models for reference evapotranspiration estimation were reliable in the areas for which they were developed. However, when applied in other region it leads to larger errors. To overcome this comparative study of reference evapotranspiration model with standard FAO56-PM or by measuring instrument was performed. The basic idea of comparison was to judge which models gives better result for specific area of interest moreover it allows comparative study of all developed model for same meteorological data and for the same condition and period of time. The main shortcoming of these developed models were they have limited area of reliability as their variables involved in the equation may not be easily available and sometimes it is difficult to compare with one another due to region specific model variables. Recognizing the above concerns, an attempt is made in this research work to analyse various existing mass transfer-based method and to develop new model for Abha Asir region of Saudi Arabia. This is because the mass-transfer approaches generally are easiest to use and often are the only practical method available. The model hence developed must be simple in nature having easily measurable variable comprises of most influencing factors with acceptable accuracy. The proposed mass-transfer (aerodynamic) based methods utilize the concept of eddy motion transfer of water vapour from an evaporating surface to the atmosphere. All such methods are based on Dalton's law. It is evident that evapotranspiration 
depends on heat energy and vapour pressure gradient and also depend on other factors, such as geological locations, seasons, etc.

The generalized expression which led to the formulation of proposed equation is as follows (Eq. 11):

$$
E T o=c\left(e_{s}-e_{a}\right)=f(u)\left(e_{s}-e_{a}\right)
$$

where ETo is reference evapotranspiration, $e_{s}$ is the saturation vapour pressure, $e_{a}$ is the vapour pressure in the air and $\mathrm{C}$ is aerodynamic conductance. The term $\mathrm{e}_{\mathrm{a}}$ is also equal to the saturation vapour pressure at the dew point temperature it is normally assumed to be dependent on wind speed. Therefore, equation 11 is expressed as the wind function $\mathrm{f}(\mathrm{u})$. This function depends on, among other factors, the observational heights of the wind speed and vapour pressure measurements. Although the two heights need not be the same, the same experimental layout must be used for a particular value of the function. Accuracy of the proposed model was measured with statistical indicators as described by Martins et al. (2017) based on regression analysis as given by Equation 12:

$$
P_{i}(y)=a 0+b 0 O_{i}(x)
$$

The regression equation (Eq. 12) represents FAO56-PM computed with observed data, Oi (x), and daily ETo computed with estimated variables, Pi (y). A value of $\mathrm{b} 0=1.0$ indicates that the fitted line is $\mathrm{y}=\mathrm{x}$, so that $\mathrm{Oi}$ and Pi are similar. A value of b0 $>1.0$ suggests over-estimation and b0 $<1.0$ under-estimation. The determination coefficient $\left(\mathrm{R}^{2}\right)$ regression between $\mathrm{Oi}$ and $\mathrm{Pi}$ showing value closer to one indicate good fit. Moreover the RMSE Value should also be checked for accuracy of result. Based on regression analysis new proposed equation has been formulated which is expressed as follows:

$$
\text { ETo }=\left(0.37+0.72 u_{2}\right) \times\left(e_{s}-e_{a}\right)
$$

Although FAO 56 PM, found to work well in numerous locations if the required data are available. However it requires measurements of temperature, relative humidity, wind speed, and solar radiation. This data demand is the main constraint on its use in locations where climate data are limited. In high mountain environments, such as the Abha Asir region, Saudi Arabia, meteorological monitoring is limited and high-quality data are scarce. Moreover measurements of relative humidity by electronic sensors are commonly plagued by hysteresis, nonlinearity and calibration errors (Allen, 1996). In order to make the study more realistic the estimated result of FAO56-PM were compared with reference evapotranspiration value measured from Davis Vantage Pro2 weather stations installed in Abha region. The instrument is affordable, accurate, durable, and easy to use and moreover real-time data for weather conditions can be easily available. It uses air temperature, relative humidity, average wind speed, and solar radiation data to estimate ETo, which is calculated once an hour. ETo requires the optional solar radiation sensor. Also the measured values from instrument were compared with proposed equation. Validation of FAO56-PM and proposed model with measured value as represented by Figure 3a-b. After evaluating FAO56-PM with measure ETo the RMSE and MBE value found to be 0.154 and $0.01 \mathrm{~mm}$ while coefficient of determination found to be 0.988 with 
slope and intercept of 1.01 and -0.03 , respectively. On the other hand while evaluating proposed model ETo with measure ETo the RMSE and MBE value found to be 0.178 and $-0.01 \mathrm{~mm}$ while coefficient of determination found to be 0.987 with slope and intercept of 1.09 and -0.249 respectively.

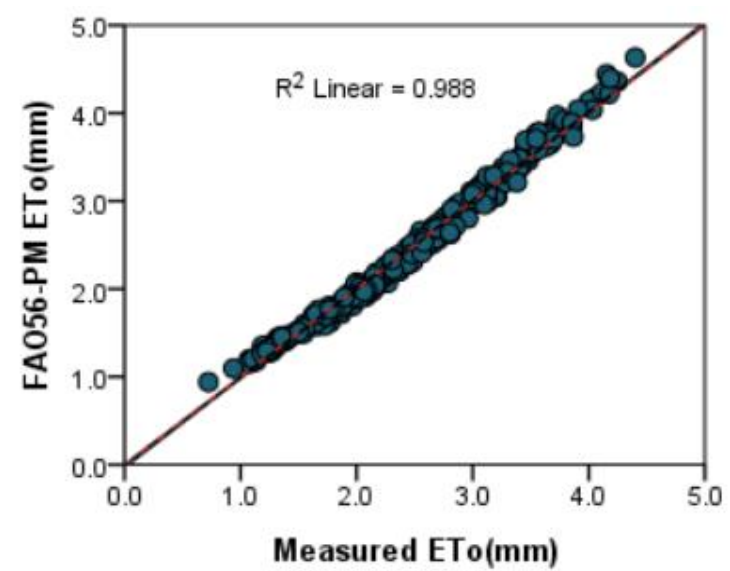

(a)

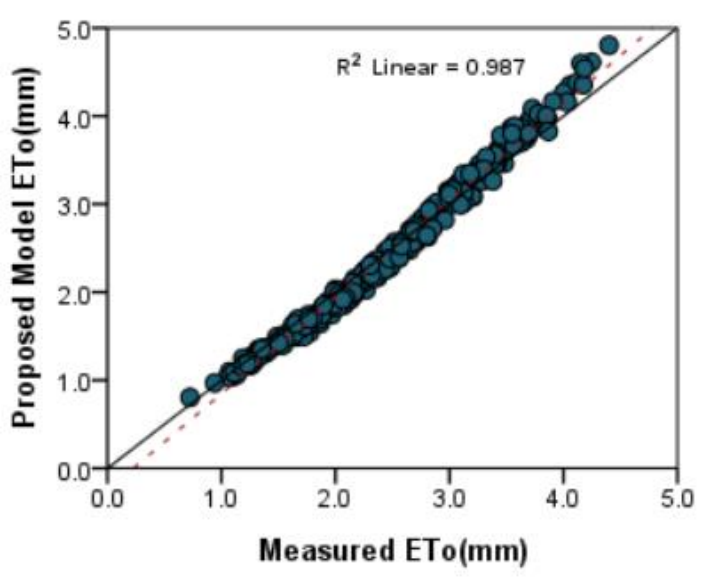

(b)

Figure 3. Validation of standard FAO56-PM ETo and proposed model ETo with measured ETo

\section{Calibration and validation of ETo equations}

The linear regression analysis has been performed to calibrate and validate the mass transfer empirical models against the FAO56 PM model (Allen et al., 1998). The specific expression is shown in the below equation:

$$
E T_{F A 056-P M}=a \cdot E T_{E M P}+b
$$

where $\mathrm{ET}_{\mathrm{FAO} 6} \mathrm{PM}$ shows the daily reference evapotranspiration estimated by the standard FAO56-PM model and $\mathrm{ET}_{\mathrm{EMP}}$ shows the ten mass transfer models respectively. The constant $\mathrm{a}$ and $\mathrm{b}$ represent calibrated empirical coefficients in the equation. In this research work, the climatic data from 1979 to 2006 were used for the development of the calibrated equations and data from 2007 to 2018 were applied for validation purpose. This partitioning is important as more data is required for the models' training. The main objective of calibrating ETo was to make the slope equally inclined to both $\mathrm{x}$ and $\mathrm{y}$ axis and intercept reaching zero. For this purpose, a linear regression was done in between Standard PM-ETo and values were obtained through the nine ETo equations. To accomplish this, calibration coefficients need to be determined which can be obtained by applying product operation to the slope of a regression line between the FAO56-PM-ETo and ETo equation by inversing the slope. This will get a new slope so that the new equation will be closer to unity. Moreover, opposite sign value of the intercept was added to get a new intercept close to zero for new regression equation. The calibration and validation of ETo estimates were performed as suggested by (Xu et al., 2013)

\section{Evaluation criteria and global performance index (GPI)}

The GPI is computed by using ten statistical measure such as Mean Absolute Error(MAE), Root Mean Square Error (RMSE), Mean Absolute Relative Error (MARE), 
Uncertainty at 95\% (U95), Root mean squared relative error (RMSRE), Relative Root Mean Square Error (RRMSE), Mean Bias Error (MBE), Coefficient of determination $\left(\mathrm{R}^{2}\right)$, Maximum Absolute Relative Error (erMax) and t-statistics (Ali et al., 2019). For Coefficient of determination $\left(\mathrm{R}^{2}\right)$ the highest value (ideally equal to 1 ) is preferable, while for all other statistical errors ideally a value of zero is preferred. Despotovic et al. (2015) proposed the GPI by scaling the values of statistical tools in between 0 and 1 , followed by subtracting the scaled values of error indicators from the corresponding medians and finally summing up the differences so obtained using the weight factors. Mathematically, for the $i^{\text {th }}$ model,

$$
G P I_{i}=\sum_{j=1}^{10} \alpha_{j}\left(\tilde{y}_{j}-\tilde{y}_{i j}\right)
$$

where, $\alpha_{j}$ have a value of +1 for statistical errors having a recommended value of 0 and a value of -1 for statistical errors that have a recommended high value of 1 (e.g. R). $\tilde{y}_{j}$ and $\tilde{y}_{i j}$ are the median and scaled values, respectively.

Willmott and Matsuura (2005) used MAE as statistical measure as shown by Equation 16:

Mean absolute error (MAE)

$$
M A E=\frac{1}{n} \sum_{i=1}^{n}\left|E T_{O, M i}-E T_{o, F A 056-P M}\right|
$$

Root mean square error

$$
R M S E=\left[\frac{1}{n} \sum_{i=1}^{n}\left(E T_{O, M i}-E T_{O, F A 056-P M}\right)^{2}\right]^{\frac{1}{2}}
$$

Mean absolute relative error (MARE)

$$
M A R E=\frac{1}{n} \sum_{i=1}^{n}\left|\frac{E T_{O, M i}-E T_{o, F A O 56-P M}}{E T_{O, M i}}\right|
$$

Behar et al. (2015) and Gueymard (2014) applied U95 in modelling of solar radiation as given by Equation 19:

Uncertainty at $95 \%$

$$
U_{95}=1.96\left(S D^{2}+R M S E^{2}\right)^{\frac{1}{2}}
$$

Root mean squared relative error

$$
R M S R E=\sqrt{\frac{1}{n} \sum_{i=1}^{n}\left(\frac{E T_{O, M i}-E T_{0, F A O 56-P M}}{E T_{O, M i}}\right)^{2}}
$$

Li et al. (2013) applied RRMSE as a statistical performance measure in the modelling of global solar radiation as given by Equation 21:

Relative root mean square error 


$$
R R M S E=100 \times \frac{\sqrt{\frac{1}{n} \sum_{i=1}^{n}\left(E T_{O, M i}-E T_{o, F A 056-P M}\right)^{2}}}{\sum_{i=1}^{n} E T_{O, M i}}
$$

Mean bias error

$$
M B E=\frac{1}{n} \sum_{i=1}^{n}\left(E T_{O, M i}-E T_{o, F A O 56-P M}\right)
$$

Correlation coefficient

$$
R^{2}=1-\frac{\sum_{i=1}^{n}\left(E T_{O, M i}-E T_{o, F A O 56-P M}\right)^{2}}{\sum_{i=1}^{n}\left(E T_{O, M i}-E T_{O, M i}\right)_{a v}}
$$

Maximum absolute relative error

$$
\operatorname{erMAX}=\max \left(\left|\frac{E T_{O, M i}-E T_{O, F A O 56-P M}}{E T_{O, M i}}\right|\right)
$$

Stone (1993) and Mulaudzi et al. (2015) t-statistics in the evaluation of solar radiation t-statistics

$$
t=\left\lceil\left.\frac{(n-1) M B E^{2}}{R M S E^{2}-M B E^{2}}\right|^{\frac{1}{2}}\right.
$$

$E T_{O, M i}=$ reference evapotranspiration by ith model; $E T_{O, E A O 56-P M}=$ reference evapotranspiration by standard model $1 ; \mathrm{SD}=$ standard deviation.

\section{Results}

The comparative study of all reference evapotranspiration equation with Standard Penman-Monteith equation is shown in Figure $4 a-j$. The plot clearly stated that the reference evapotranspiration value from all the ten equations has a high correlation with the FA056-PM with the coefficient of determination $\mathrm{R}^{2}$ range from 0.89 to 0.96 The highest correlation was shown by proposed model while the lowest correlation by Meyer model. The best fit of a model is measured by the linear regression line slope close to unity and the intercept to zero. The variation of slope and intercept for all models is shown in Table 2. While evaluating the performance of mass transfer equation against Standard FAO56-PM, the best estimates as shown in Table 3 were obtained by proposed equation with $\mathrm{R}^{2}=0.96, \mathrm{MAE}=0.2 \mathrm{~mm} / \mathrm{day} ; \mathrm{RMSE}=0.23$ $\mathrm{mm} /$ day; $\quad \mathrm{MARE}=0.1 ; \quad \mathrm{U} 95=1.05 \% ; \quad \mathrm{RMSRE}=0.12 ; \quad \mathrm{RRMSE}=0.09 ;$ $\mathrm{MBE}=0.2 \mathrm{~mm} /$ day; $\operatorname{erMax}=0.23 ; \mathrm{t}$-statistic $=18.47 \mathrm{~mm} /$ day. Moreover the GPA value shows highest score. Similarly worst outcome was shown by Trabert model. The computed GPI value during evaluation, calibration and validating the calibrated model are shown in Tables 4-6. The comparative study of global performance index during evaluation is shown in Figure 5.

The main objective of the model calibration is to improve the performance of all equations. The computed result from the year 1979 to 2006 was used to calibrate the evapotranspiration equation. From the result for calibrated model (Fig. 6a-j), it can be observed that the coefficient for determination improved substantially with values of $\mathrm{R}^{2}$ ranges from 0.9 to 0.987 whereby high correlation was shown by proposed model and 
lower value by Meyer method. While evaluating the performance of mass transfer equation against standard FAO56-PM after calibration the best estimates were obtained by proposed equation with high coefficient of determination $\mathrm{R}^{2}=0.987$, MAE $=0.07 \mathrm{~mm} /$ day; $\quad$ RMSE $=0.09 \mathrm{~mm} /$ day; $\quad$ MARE $=0.03 ; \quad \mathrm{U} 95=0.85 \%$; RMSRE $=0.04 ; \quad$ RRMSE $=0.04 ; \quad \operatorname{MBE}=0.07 \quad \mathrm{~mm} /$ day; $\quad \operatorname{erMax}=0.1 ; \quad \mathrm{t}-$ statistic $=13.48 \mathrm{~mm} /$ day as shown by Table 3. Moreover, the GPA Value shows that proposed highest score as shown by Table 5. Similarly, worst outcome was shown by Meyer model.

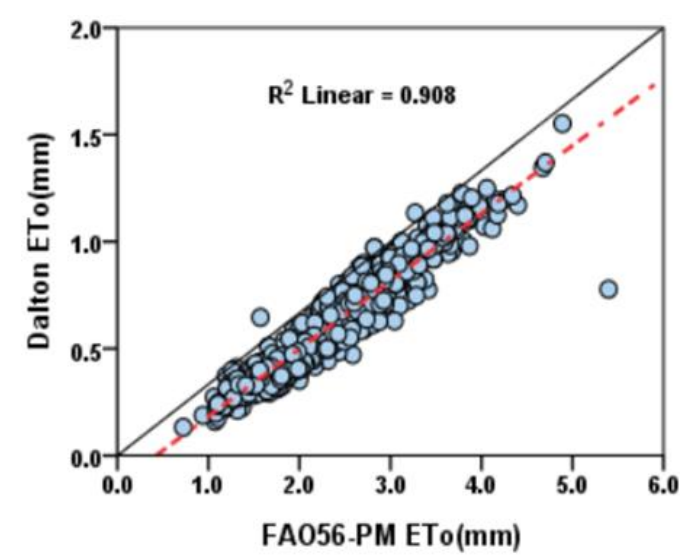

(a)

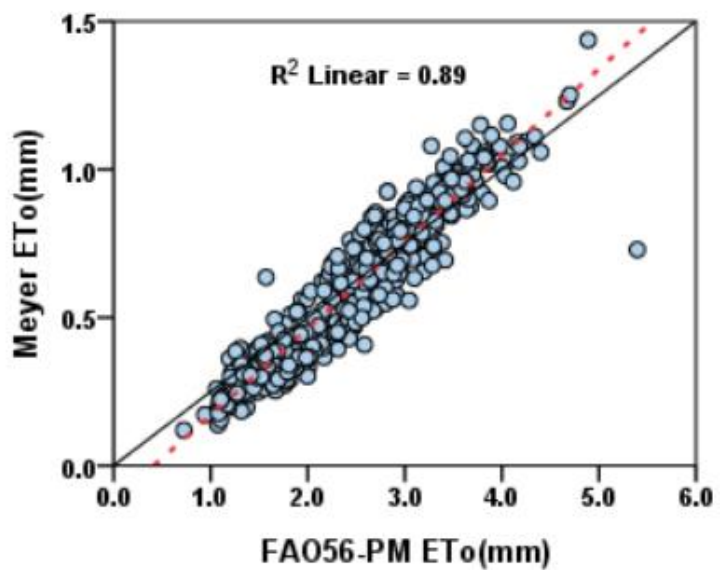

(c)

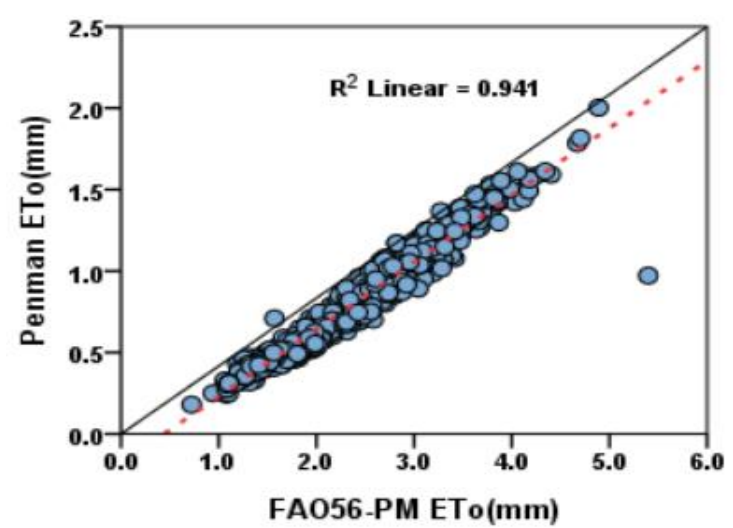

(e)

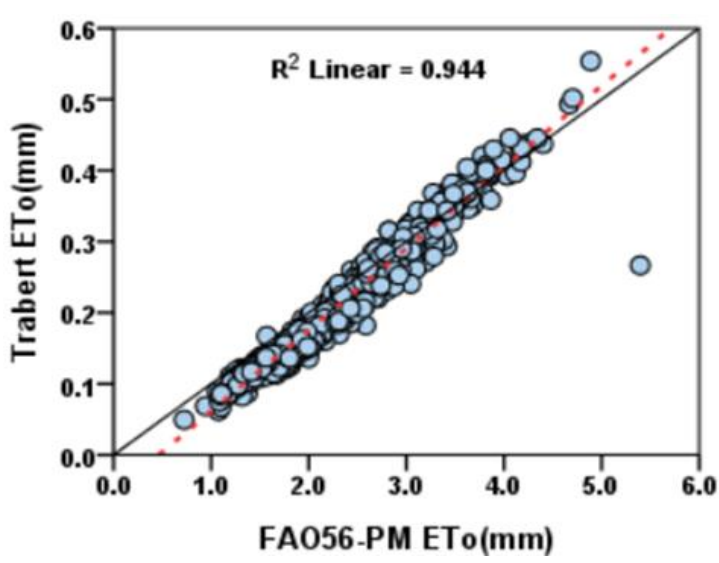

(b)

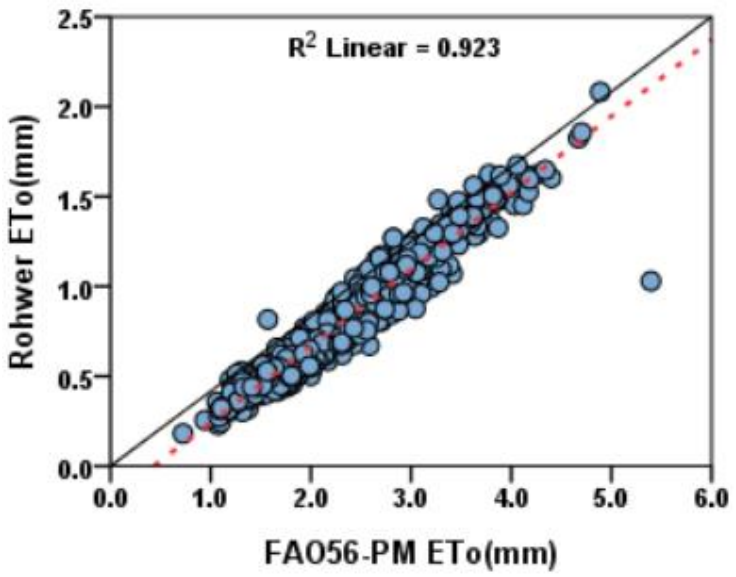

(d)

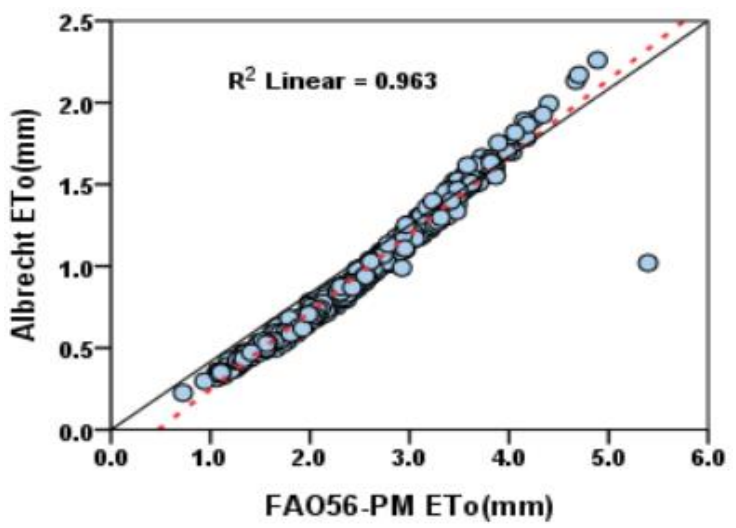

(f) 


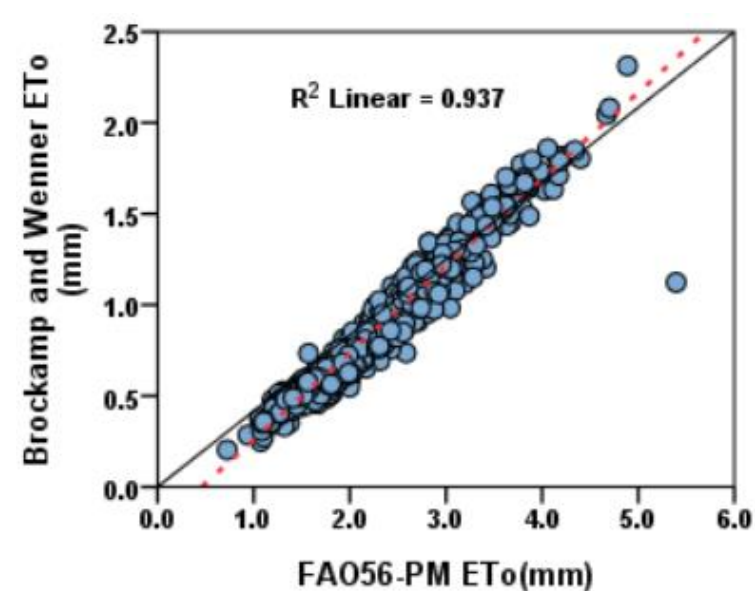

(g)

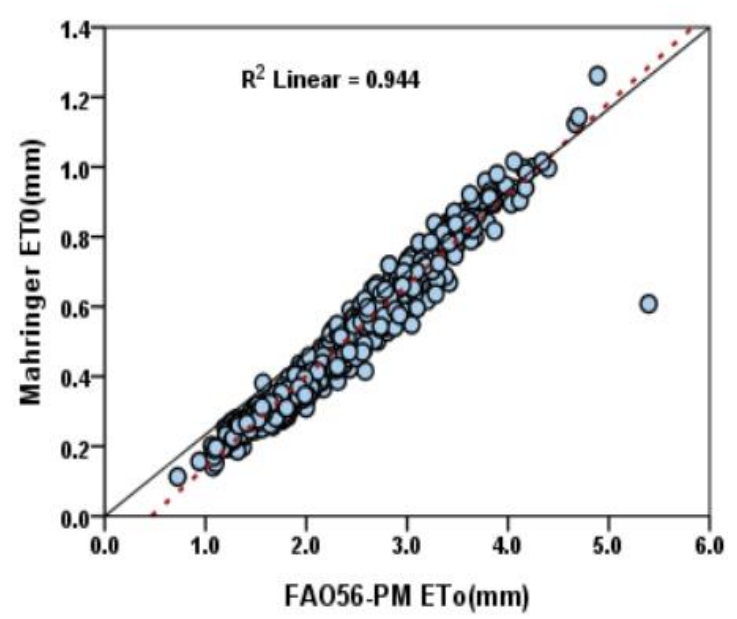

(i)

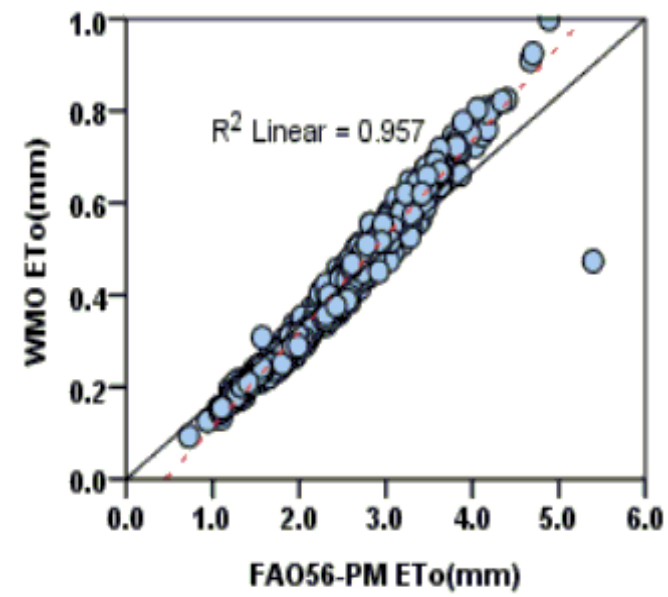

(h)

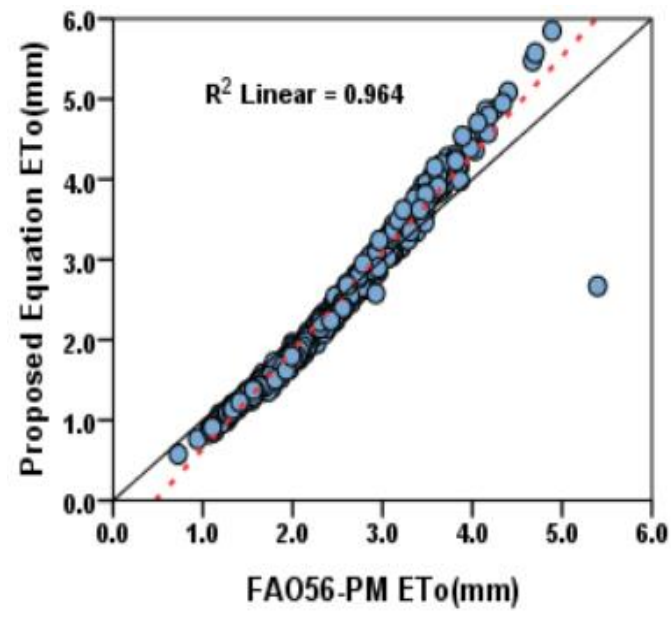

(j)

Figure 4. Relationship between the daily ETo estimates of each method versus the FAO56-PM at Asir region for the 1979-2018 period

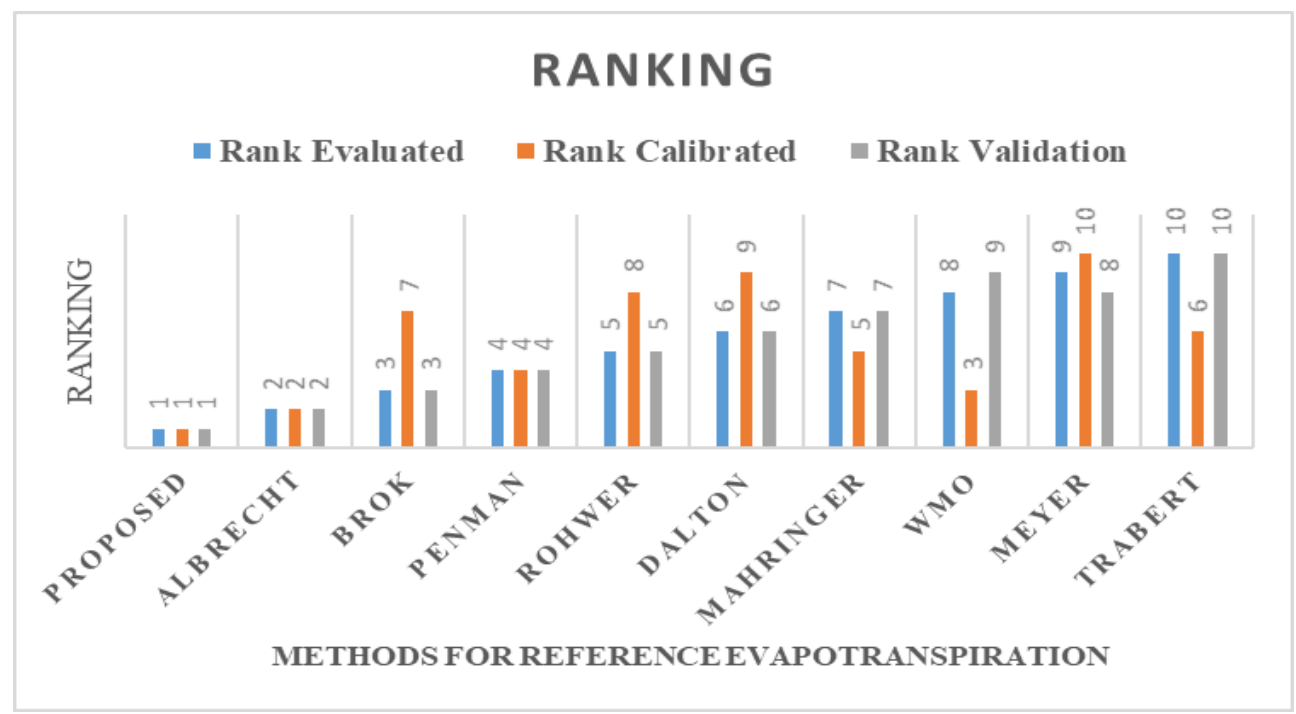

Figure 5. Comparison of ranking of ETo estimates based on ETo equation, calibrated equation and validating the calibrated equation 
Table 2. Slope and intercept of all model during evaluation, calibration and validation against FAO56-PM

\begin{tabular}{c|c|c|c|c|c|c}
\hline Sno & \multicolumn{2}{|c|}{ Evaluation } & \multicolumn{2}{c|}{ Calibration } & \multicolumn{2}{c}{ Validation } \\
\hline Method & Slope & Intercept & Slope & Intercept & Slope & Intercept \\
\hline Dalton (1802) & 0.316 & -0.134 & 1.02 & -0.036 & 0.301 & -0.079 \\
Trabert (1896) & 0.114 & -0.05 & 1.01 & -0.058 & 0.109 & 0.012 \\
Meyer (1926) & 0.29 & -0.122 & 1.02 & -0.037 & 0.275 & -0.068 \\
Rohwer (1931) & 0.426 & -0.183 & 1.01 & -0.036 & 0.406 & -0.121 \\
Penman (1948) & 0.412 & -0.181 & 1.01 & -0.034 & 0.39 & 0.120 \\
Albrecht (1950) & 0.473 & -0.225 & 1.01 & -0.031 & 0.455 & -0.156 \\
Brockamp (1963) & 0.476 & -0.218 & 1.01 & -0.034 & 0.455 & -0.152 \\
WMO (1966) & 0.206 & -0.09 & 1.01 & -0.033 & 0.198 & -0.046 \\
Mahringer (1970) & 0.261 & -0.12 & 1.01 & -0.034 & 0.249 & -0.068 \\
Proposed (2019) & 1.22 & -0.575 & 1.01 & -0.031 & 1.17 & -0.449 \\
\hline
\end{tabular}

Table 3. Statistical measures of all model during evaluation, calibration and validation against FAO56-PM

\begin{tabular}{|c|c|c|c|c|c|c|c|c|c|c|c|}
\hline \multirow{11}{*}{ 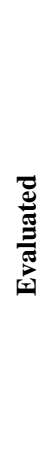 } & & Dalton & Trabert & Meyer & Rohwer & Penman & Albrecht & Brockamp & WMO & Mahringer & Proposed \\
\hline & MAE & 1.83 & 2.21 & 1.88 & 1.62 & 1.64 & 1.50 & 1.53 & 2.03 & 1.93 & 0.20 \\
\hline & RMSE & 1.91 & 2.33 & 1.97 & 1.69 & 1.71 & 1.56 & 1.59 & 2.13 & 2.03 & 0.23 \\
\hline & MARE & 3.30 & 10.80 & 3.72 & 2.17 & 2.23 & 1.73 & 1.85 & 5.35 & 4.18 & 0.10 \\
\hline & U95\% & 1.93 & 2.33 & 1.98 & 1.72 & 1.74 & 1.61 & 1.64 & 2.14 & 2.04 & 1.06 \\
\hline & RMSRE & 3.37 & 10.91 & 3.81 & 2.22 & 2.27 & 1.75 & 1.89 & 5.39 & 4.23 & 0.12 \\
\hline & RRMSE & 3.20 & 10.73 & 3.58 & 2.08 & 2.17 & 1.69 & 1.76 & 5.34 & 4.10 & 0.10 \\
\hline & MBE & 1.83 & 2.21 & 1.88 & 1.62 & 1.64 & 1.50 & 1.53 & 2.03 & 1.93 & 0.20 \\
\hline & $\mathrm{R}^{2}$ & 0.91 & 0.94 & 0.89 & 0.92 & 0.94 & 0.96 & 0.94 & 0.96 & 0.94 & 0.96 \\
\hline & erMax & 5.71 & 16.38 & 6.82 & 3.70 & 3.46 & 2.80 & 3.32 & 7.06 & 6.62 & 0.24 \\
\hline & T-STAT & 32.15 & 30.09 & 31.85 & 33.78 & 33.55 & 34.56 & 34.95 & 30.86 & 31.54 & 18.48 \\
\hline \multirow{11}{*}{ 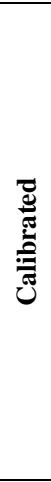 } & & Dalton & Trabert & Meyer & Rohwer & Penman & Albrecht & Brockamp & WMO & Mahringer & Proposed \\
\hline & MAE & 0.16 & 0.12 & 0.18 & 0.14 & 0.11 & 0.08 & 0.12 & 0.09 & 0.11 & 0.07 \\
\hline & RMSE & 0.20 & 0.15 & 0.22 & 0.18 & 0.14 & 0.10 & 0.16 & 0.11 & 0.15 & 0.09 \\
\hline & MARE & 0.08 & 0.06 & 0.09 & 0.07 & 0.05 & 0.03 & 0.06 & 0.04 & 0.05 & 0.03 \\
\hline & U95\% & 0.87 & 0.86 & 0.89 & 0.87 & 0.86 & 0.85 & 0.86 & 0.85 & 0.86 & 0.85 \\
\hline & RMSRE & 0.11 & 0.08 & 0.12 & 0.09 & 0.07 & 0.04 & 0.08 & 0.05 & 0.07 & 0.04 \\
\hline & RRMSE & 0.09 & 0.07 & 0.10 & 0.08 & 0.06 & 0.04 & 0.07 & 0.05 & 0.06 & 0.04 \\
\hline & MBE & 0.16 & 0.12 & 0.18 & 0.14 & 0.11 & 0.08 & 0.12 & 0.09 & 0.11 & 0.07 \\
\hline & $\mathrm{R}^{2}$ & 0.92 & 0.96 & 0.90 & 0.94 & 0.96 & 0.99 & 0.95 & 0.98 & 0.96 & 0.99 \\
\hline & erMax & 0.25 & 0.18 & 0.30 & 0.21 & 0.16 & 0.13 & 0.19 & 0.12 & 0.17 & 0.10 \\
\hline & T-STAT & 12.62 & 11.63 & 13.10 & 12.09 & 11.47 & 13.11 & 11.36 & 13.37 & 11.31 & 13.48 \\
\hline \multirow{11}{*}{ 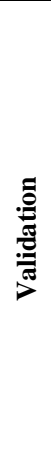 } & & Dalton & Trabert & Meyer & Rohwer & Penman & Albrecht & Brockamp & WMO & Mahringer & Proposed \\
\hline & MAE & 1.92 & 2.34 & 1.98 & 1.69 & 1.72 & 1.59 & 1.59 & 2.16 & 2.05 & 0.20 \\
\hline & RMSE & 2.01 & 2.46 & 2.07 & 1.76 & 1.79 & 1.65 & 1.65 & 2.26 & 2.14 & 0.25 \\
\hline & MARE & 2.82 & 7.79 & 3.16 & 1.88 & 1.97 & 1.60 & 1.60 & 4.65 & 3.60 & 0.08 \\
\hline & U95\% & 2.03 & 2.46 & 2.09 & 1.80 & 1.83 & 1.70 & 1.70 & 2.27 & 2.16 & 1.11 \\
\hline & RMSRE & 2.86 & 7.82 & 3.21 & 1.91 & 1.99 & 1.61 & 1.63 & 4.67 & 3.63 & 0.10 \\
\hline & RRMSE & 2.82 & 8.17 & 3.16 & 1.86 & 1.95 & 1.57 & 1.57 & 4.74 & 3.64 & 0.10 \\
\hline & MBE & 1.92 & 2.34 & 1.98 & 1.69 & 1.72 & 1.59 & 1.59 & 2.16 & 2.05 & 0.20 \\
\hline & $\mathrm{R}^{2}$ & 0.89 & 0.91 & 0.87 & 0.89 & 0.90 & 0.92 & 0.90 & 0.91 & 0.91 & 0.92 \\
\hline & erMax & 3.79 & 9.37 & 4.32 & 2.57 & 2.56 & 2.10 & 2.22 & 5.45 & 4.48 & 0.23 \\
\hline & T-STAT & 32.52 & 30.72 & 32.20 & 33.82 & 33.91 & 35.67 & 35.03 & 31.78 & 32.30 & 12.58 \\
\hline
\end{tabular}


Table 4. Ranking based on global performance index for various methods during evaluation period (1979-2018)

\begin{tabular}{c|c|c|c|c|c|c|c|c|c|c|c|c}
\hline Method & MAE & RMSE & MARE & U95\% & RMSRE & RRMSE & MBE & $\mathbf{R}^{\mathbf{2}}$ & erMax & T-STAT & GP1 & Rank \\
\hline Proposed & 0.76 & 0.75 & 0.25 & 0.61 & 0.25 & 0.24 & 0.76 & -0.29 & 0.28 & 0.82 & 5.02 & 1 \\
Albrecht & 0.12 & 0.12 & 0.10 & 0.18 & 0.10 & 0.09 & 0.12 & -0.27 & 0.12 & -0.16 & 1.05 & 2 \\
Brockamp & 0.10 & 0.11 & 0.09 & 0.16 & 0.09 & 0.09 & 0.10 & 0.08 & 0.09 & -0.18 & 0.56 & 3 \\
Penman & 0.05 & 0.05 & 0.05 & 0.07 & 0.05 & 0.05 & 0.05 & 0.02 & 0.08 & -0.09 & 0.33 & 4 \\
Rohwer & 0.06 & 0.06 & 0.06 & 0.09 & 0.06 & 0.06 & 0.06 & 0.27 & 0.06 & -0.11 & 0.12 & 5 \\
Dalton & -0.05 & -0.05 & -0.05 & -0.07 & -0.05 & -0.05 & -0.05 & 0.47 & -0.06 & -0.01 & -0.91 & 6 \\
Mahringer & -0.10 & -0.10 & -0.13 & -0.16 & -0.13 & -0.13 & -0.10 & -0.02 & -0.12 & 0.03 & -0.93 & 7 \\
WMO & -0.15 & -0.15 & -0.24 & -0.23 & -0.24 & -0.25 & -0.15 & -0.18 & -0.15 & 0.07 & -1.31 & 8 \\
Meyer & -0.07 & -0.07 & -0.09 & -0.11 & -0.09 & -0.08 & -0.07 & 0.71 & -0.13 & 0.01 & -1.43 & 9 \\
Trabert & -0.24 & -0.25 & -0.75 & -0.39 & -0.75 & -0.76 & -0.24 & -0.02 & -0.72 & 0.12 & -3.95 & 10 \\
\hline
\end{tabular}

Table 5. Ranking based on global performance index for various methods during calibration period (1979-2006)

\begin{tabular}{c|c|c|c|c|c|c|c|c|c|c|c|c}
\hline Method & MAE & RMSE & MARE & U95\% & RMSRE & RRMSE & MBE & R $^{2}$ & erMax & T-STAT & GP1 & Rank \\
\hline Proposed & 0.38 & 0.44 & 0.38 & 0.26 & 0.42 & 0.44 & 0.38 & -0.30 & 0.36 & -0.52 & 2.85 & 1 \\
Albrecht & 0.34 & 0.40 & 0.36 & 0.21 & 0.39 & 0.41 & 0.34 & -0.28 & 0.25 & -0.35 & 2.63 & 2 \\
WMO & 0.24 & 0.31 & 0.26 & 0.26 & 0.31 & 0.30 & 0.24 & -0.19 & 0.27 & -0.47 & 1.92 & 3 \\
Penman & 0.04 & 0.04 & 0.05 & 0.09 & 0.06 & 0.04 & 0.04 & 0.02 & 0.08 & 0.41 & 0.82 & 4 \\
Mahringer & 0.04 & 0.03 & 0.04 & 0.04 & 0.04 & 0.04 & 0.04 & -0.02 & 0.04 & 0.48 & 0.81 & 5 \\
Trabert & -0.04 & -0.03 & -0.04 & -0.07 & -0.04 & -0.04 & -0.04 & -0.02 & -0.04 & 0.34 & 0.02 & 6 \\
Brok & -0.06 & -0.07 & -0.06 & -0.04 & -0.07 & -0.07 & -0.06 & 0.07 & -0.08 & 0.46 & -0.12 & 7 \\
Rohwer & -0.24 & -0.23 & -0.23 & -0.16 & -0.21 & -0.23 & -0.24 & 0.27 & -0.19 & 0.12 & -1.88 & 8 \\
Dalton & -0.45 & -0.41 & -0.44 & -0.36 & -0.41 & -0.42 & -0.45 & 0.46 & -0.39 & -0.12 & -3.91 & 9 \\
Meyer & -0.62 & -0.56 & -0.62 & -0.74 & -0.58 & -0.56 & -0.62 & 0.70 & -0.64 & -0.34 & -5.97 & 10 \\
\hline
\end{tabular}

Table 6. Ranking based on global performance index for various methods during validation period (2007-2018)

\begin{tabular}{c|c|c|c|c|c|c|c|c|c|c|c|c}
\hline Method & MAE & RMSE & MARE & U95\% & RMSRE & RRMSE & MBE & $\mathbf{R}^{\mathbf{2}}$ & erMax & T-STAT & GP1 & Rank \\
\hline Proposed & 0.76 & 0.75 & 0.30 & 0.61 & 0.30 & 0.28 & 0.76 & -0.26 & 0.32 & 0.86 & 5.19 & 1 \\
Albrecht & 0.11 & 0.12 & 0.10 & 0.17 & 0.11 & 0.10 & 0.11 & -0.23 & 0.12 & -0.14 & 1.02 & 2 \\
Brok & 0.11 & 0.11 & 0.10 & 0.17 & 0.10 & 0.10 & 0.11 & 0.07 & 0.10 & -0.11 & 0.73 & 3 \\
Penman & 0.05 & 0.05 & 0.06 & 0.08 & 0.06 & 0.05 & 0.05 & 0.02 & 0.07 & -0.06 & 0.37 & 4 \\
Rohwer & 0.06 & 0.06 & 0.07 & 0.10 & 0.07 & 0.07 & 0.06 & 0.28 & 0.07 & -0.06 & 0.21 & 5 \\
Dalton & -0.05 & -0.05 & -0.06 & -0.08 & -0.06 & -0.05 & -0.05 & 0.47 & -0.07 & 0.00 & -0.92 & 6 \\
Mahringer & -0.11 & -0.11 & -0.16 & -0.17 & -0.16 & -0.16 & -0.11 & -0.02 & -0.14 & 0.00 & -1.07 & 7 \\
Meyer & -0.07 & -0.08 & -0.10 & -0.12 & -0.10 & -0.10 & -0.07 & 0.74 & -0.13 & 0.01 & -1.50 & 8 \\
WMO & -0.16 & -0.16 & -0.29 & -0.25 & -0.29 & -0.29 & -0.16 & -0.19 & -0.25 & 0.03 & -1.64 & 9 \\
Trabert & -0.24 & -0.25 & -0.70 & -0.39 & -0.70 & -0.72 & -0.24 & -0.02 & -0.68 & 0.07 & -3.82 & 10 \\
\hline
\end{tabular}

Ten calibrated evapotranspiration equations have been validated for the period of 2007-2018 in order to show which calibrated equation perform well and can be further employed as an alternative to Standard FAO Penman Monteith model. From output of validation of calibrated equation (Fig. $7 a-i$ ), it can be observed that the coefficient of 
determination ranges from 0.87 to 0.92 with high correlation shown by Proposed model and lower value by Meyer model. While evaluating the performance of mass transfer equation against Standard FAO56-PM during validation of calibrated equation, the best estimates were obtained by proposed equation with high determination coefficient $\left(\mathrm{R}^{2}=0.92 ; \mathrm{MAE}=0.19 \mathrm{~mm} /\right.$ day; $\mathrm{MSE}=0.09 \mathrm{~mm} / \mathrm{day} ; \mathrm{MARE}=0.03 ; \mathrm{U} 95=0.85$; RMSRE $=0.04 ; \quad$ RRMSE $=0.04 ; \quad \operatorname{MBE}=0.07 \quad \mathrm{~mm} /$ day; $\quad$ erMax $=0.1 ; \quad \mathrm{t}-$ Statistics $=13.48 \mathrm{~mm} /$ day as shown by Table 3. Moreover, the GPA Value shows highest score as shown by Table 6. Similarly, worst outcome was shown by Meyer model.

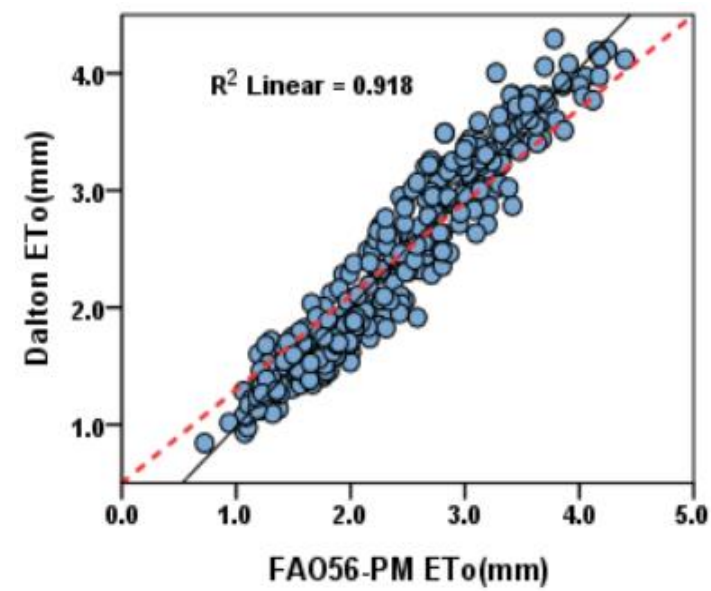

(a)

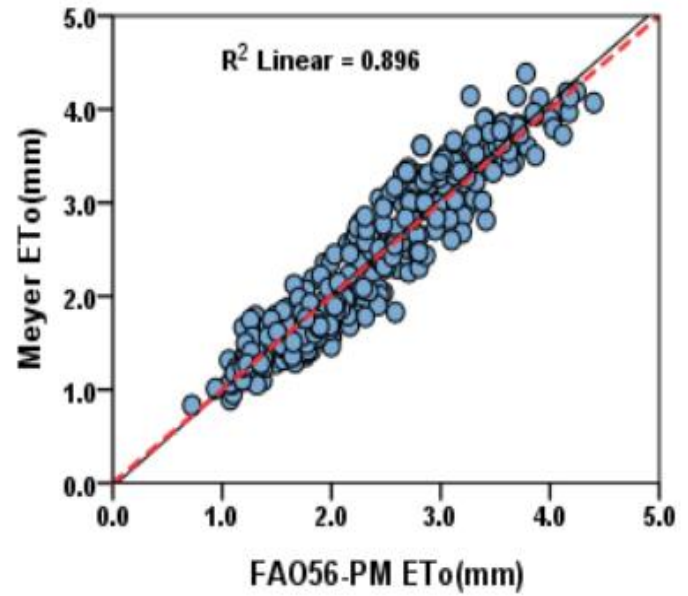

(c)

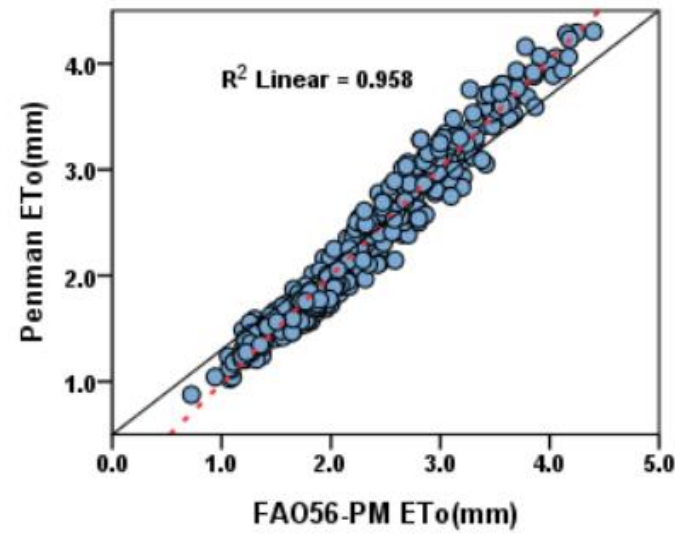

(e)

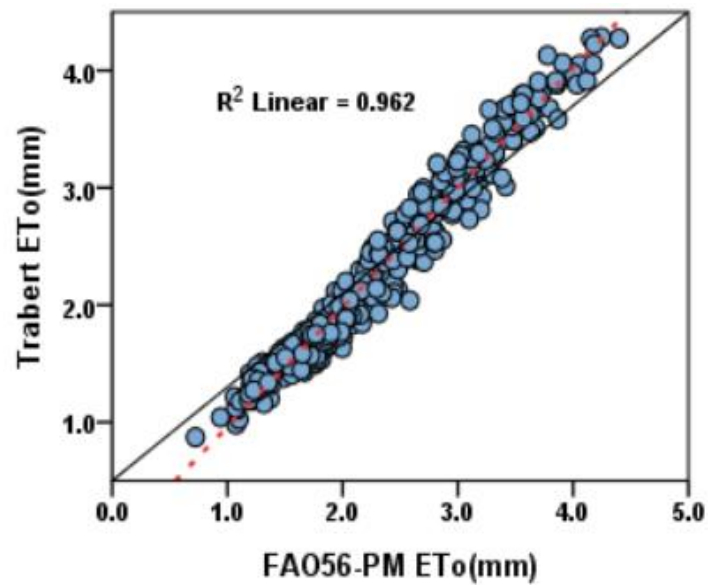

(b)

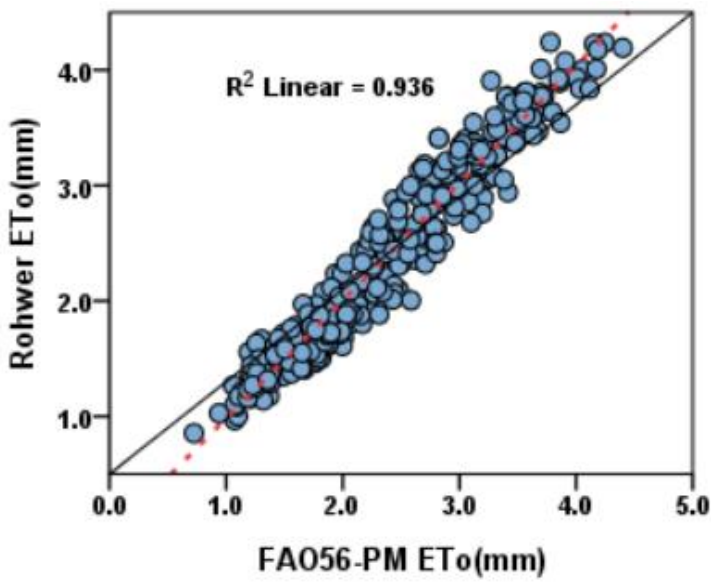

(d)

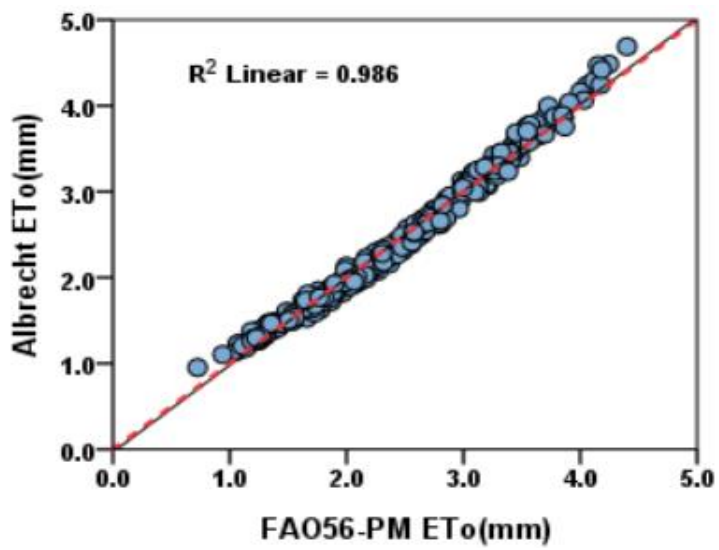

(f) 


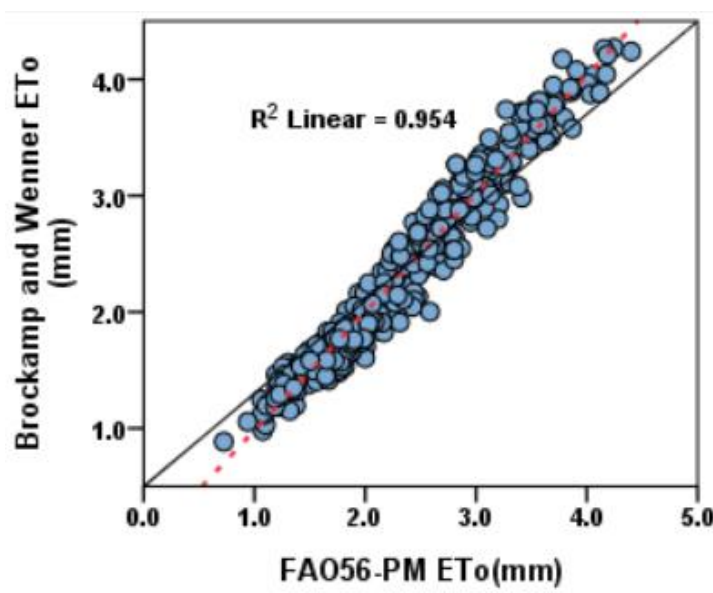

$(\mathrm{g})$

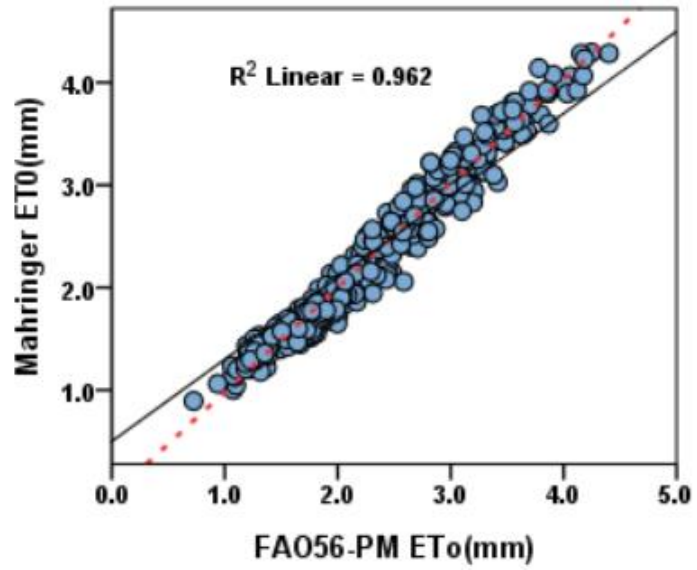

(i)

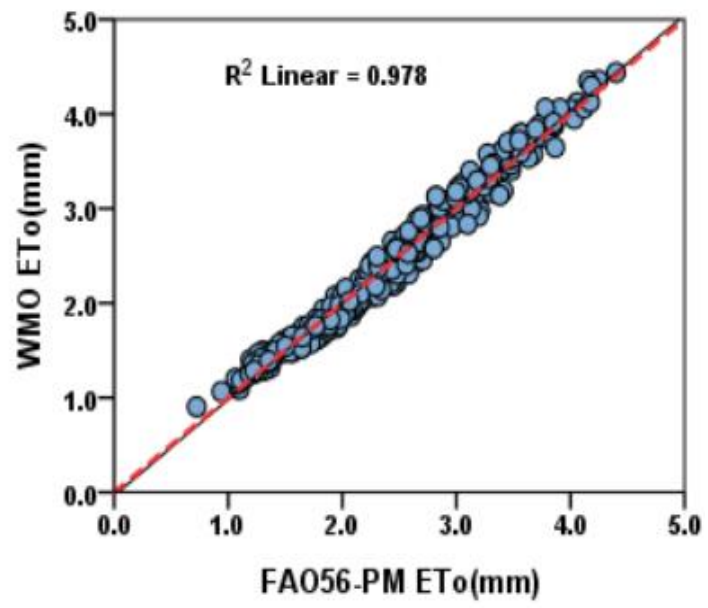

(h)

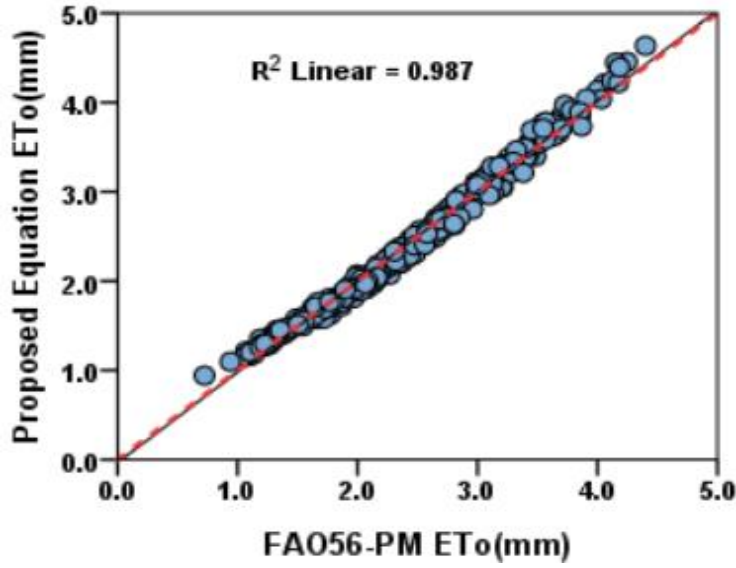

(j)

Figure 6. Relationship between the calibrated daily ETo estimates of each method versus the FAO56-PM at Asir region for the 1979-2006 period

\section{Discussion}

Different ETo models were used around the world to compute the reference evapotranspiration by using various climatic parameters such as mean temperature $(\mathrm{Tm})$, relative humidity $(\mathrm{RH})$ solar radiation (Rs) and wind speed $(\mathrm{u})$ ). FAO56-PM model is the most accurate model for estimating the ETo over the past few decades. But due to the constraint of limited climatic parameters, alternative equation has to be found out. Thus, to find an alternative technique of accurate prediction of ETo under climatic condition, the performance of the nine mass models and one proposed model were evaluated against the FAO56-PM model by using the ten common statistical approaches. Additionally, a linear regression model was adopted to calibrate and validate the performance of the empirical models during the 1979-2006 and 2007-2018 time periods respectively. The result evaluated from 1979 to 2018 showed that the proposed mass transfer method performed better without calibration with the highest coefficient of determination $\left(\mathrm{R}^{2}=0.96\right)$. The statistical output showed that the proposed model performed better as compared to the other model. The models are calibrated similar to the studies of Irmak et al. (2003) and Xu and Singh (2001). Valipour (2015) indicated overestimation of ETo by mass transfer-based equations, compared to the 
Penman-Monteith model similar to the results reported by Winter et al. (1995). The Penman equation was the best performing equation among mass transfer equations across 15 provinces in Iran with the least ETo overestimate of $0.03 \mathrm{~mm} / \mathrm{day}$ as the Papadakis equation (Valipour, 2015). The Trabert and Mahringer equations performed relatively well under the sahelian climatic conditions as reported by Djaman et al. (2015). Tabari et al. (2013) reported that Trabert and Mahringer equations underestimated ETo with average error of $26 \%$ and $31 \%$, respectively in Iran while (Djaman et al., 2015) reported average ETo underestimation of $16 \%$ and $31 \%$ at Ndiaye (coastal area) and at Fanaye (inland area) in the Senegal River Valley and Delta, respectively. Adversely, poor performance of the Mahringer equation was reported in Poland (Bogawski and Bednorz, 2014). Singh and Xu (2002) indicated reasonable performance of the Meyer, Dalton, and Rohwer equation for free water evaporation estimation from four weather stations in north-western Ontario, Canada. The results of this study showed the specificity of each ETo equation and this might have been due to the sensitivity of the models to the climatic variables used in each model (Valipour, 2015). The performance of mass transfer empirical methods was evaluated against FAO56-PM method owing to its, rigorousness, comprehensiveness as from the work of several researchers (e.g. Ali and Shui, 2009; Tabari et al., 2013). After calibrating the empirical equation from (1979-2006), it was observed that there was a remarkable improvement in the performance of these nine equations. Additionally, the findings revealed that the calibration improved the reliability and consistency of different $\mathrm{ET}_{0}$ equations. The correlation value significantly increased. Moreover, the statistical measures such as RMSE, SEE, MBE and PE significantly reduced for all the models.

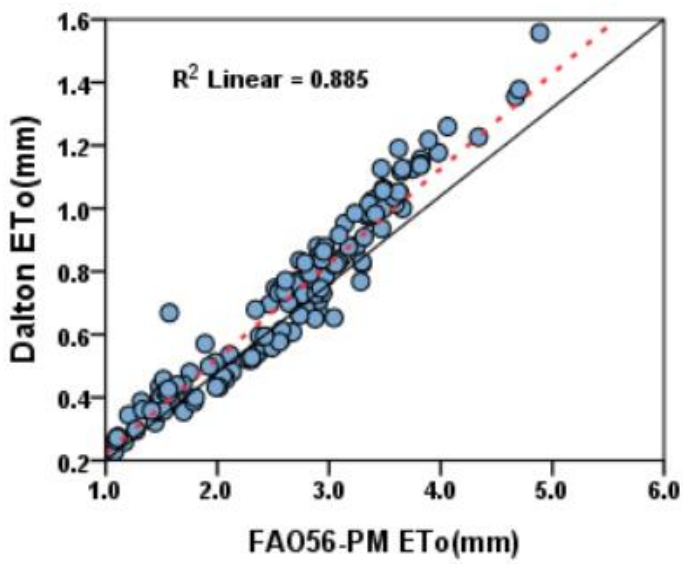

(a)

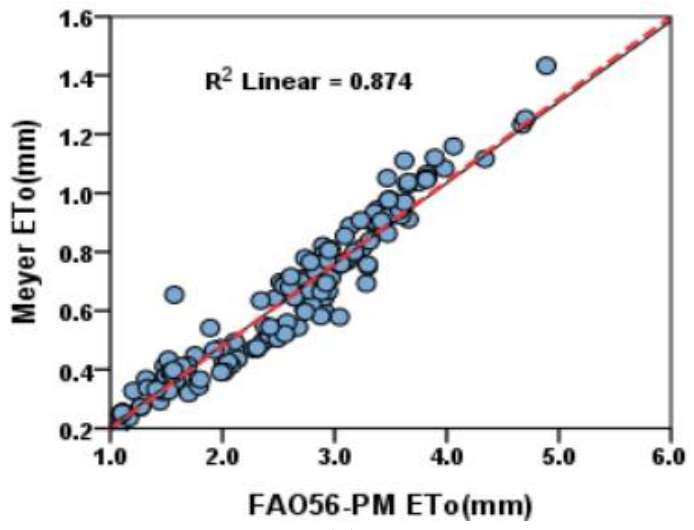

(c)

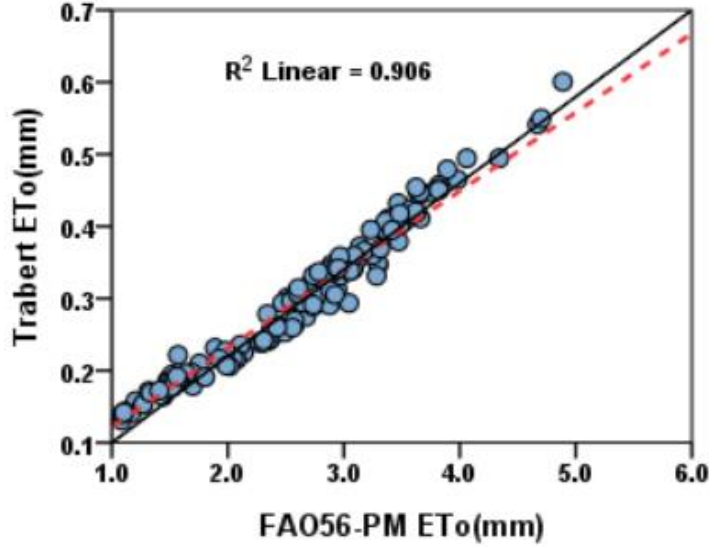

(b)

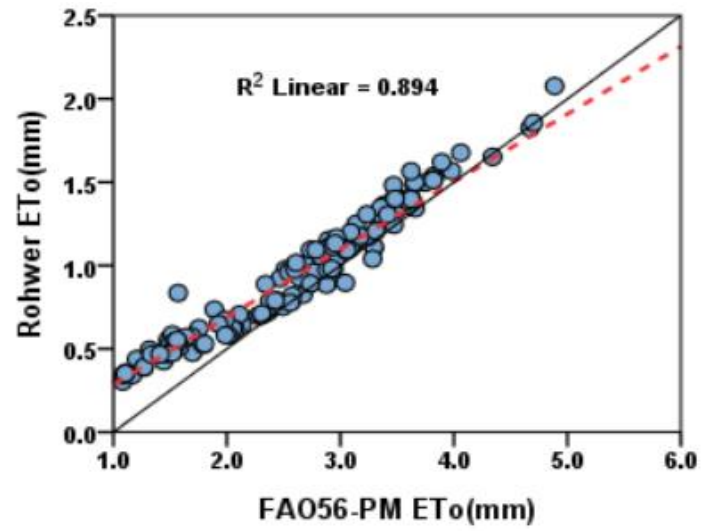

(d) 


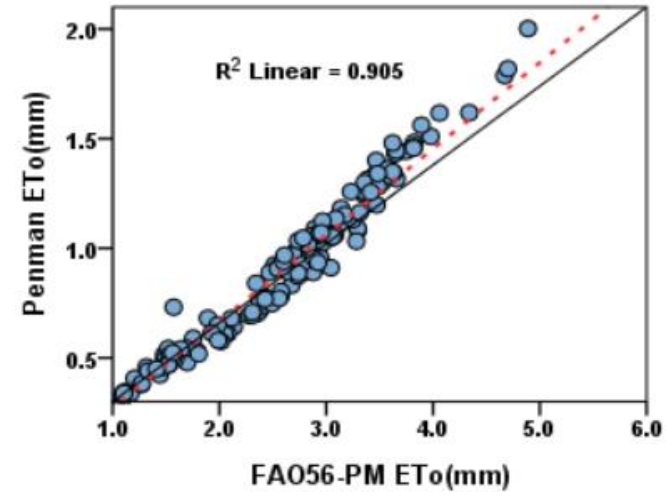

(e)

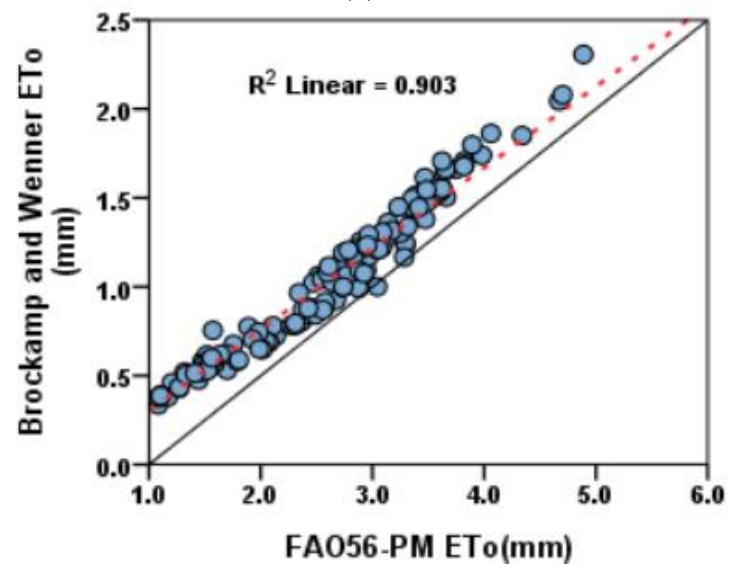

(g)

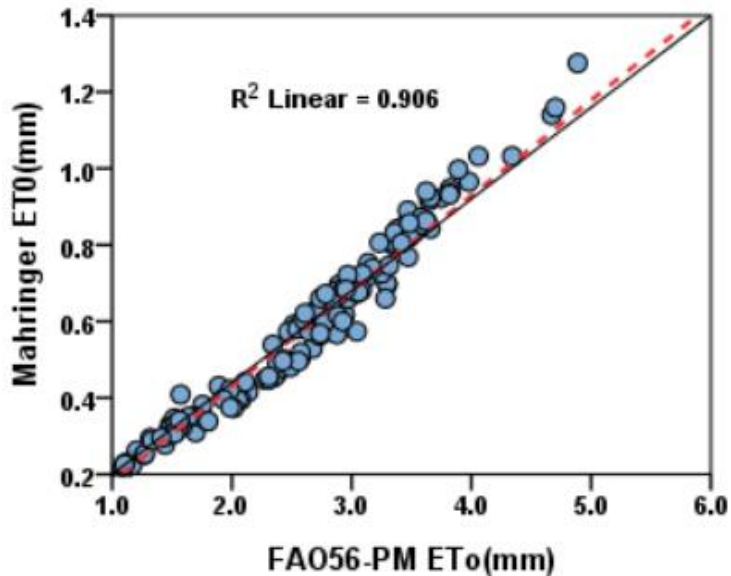

(i)

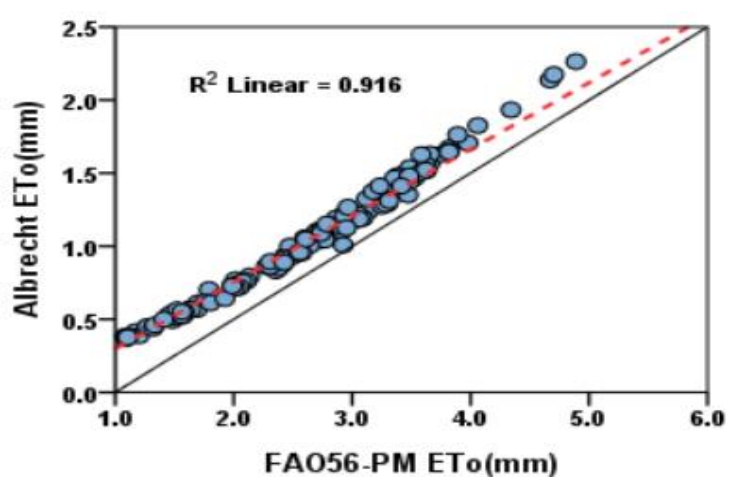

(f)

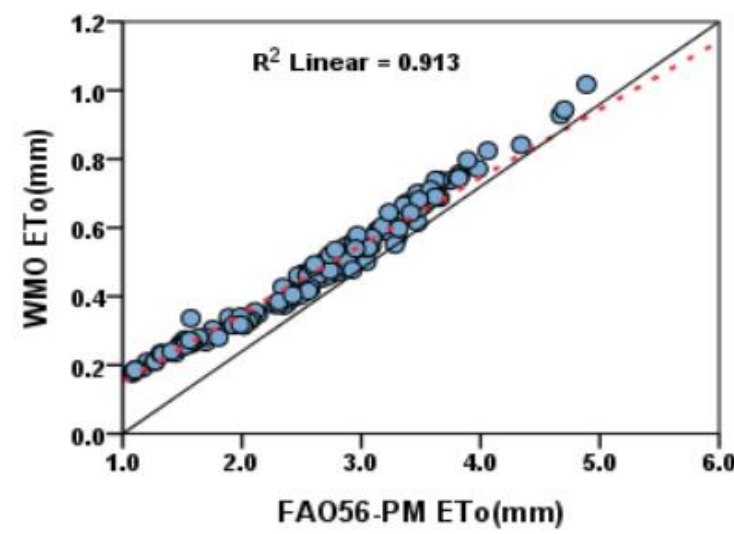

(h)

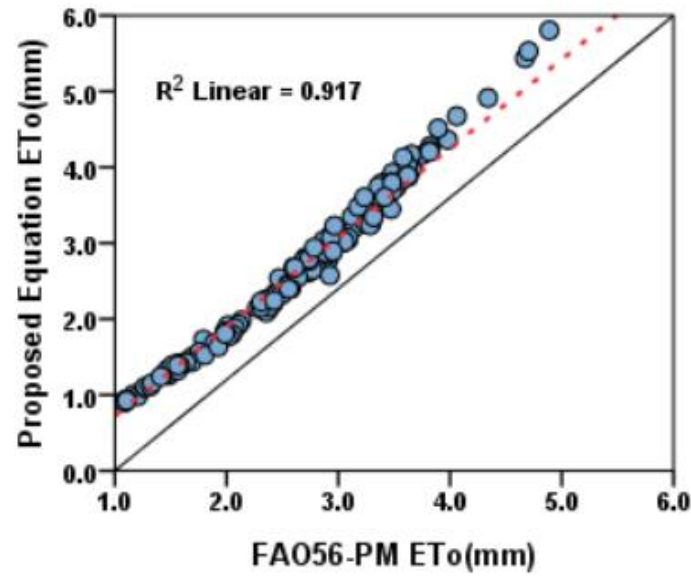

(j)

Figure 7. Relationship between the validation of calibrated daily ETo estimates of each method versus the FAO56-PM at Asir region for the 2007-2018 period

Valipour (2015) reported that there was an improvement in the calibrated Trabert and Mahringer equations in Iran with MBE as low as $0.02 \mathrm{~mm} /$ day. He indicated that the Trabert model can skip the calibration process to generate the best performance in Iran. The dependency of mass transfer equation on the vapor pressure was too small. It was reported that better performance of the Trabert and Mahringer equations were in inland area than at the coastal area in the Senegal River Valley (Djaman et al., 2015). The validation of the nine ETo equations for the 2007-2018 period is presented in Figure 6. 
The statistical analysis showed a strong correlation between the calibrated equations to the PM estimates (Table 4). The findings of the research are in agreement with Kisi and Zounemat Kermani (2014). The outcomes of the study will provide meaningful guidance for agricultural production, hydrological planning and management in the vital region as well as other regions with similar climates.

\section{Conclusions}

The current study was performed with an aim to evaluate the ten reference evapotranspiration models (nine mass transfers and one proposed model) with respect to standard FAO56 PM model in the semi-arid region of Kingdom of Saudi Arabia. The ten evapotranspiration models have been successfully evaluated (period: 1979-2018), calibrated (period: 1979-2006) and further validated (period: 2007-2018). Based on the evaluation criteria, the GPI has been computed and the ranking operation was performed in order to observe the performance against the FAO56 PM equation under the available climatic conditions in Asir region. The effectiveness of the evaluated models can be judged based on the regression and statistical evaluation criteria which can be summarized as below:

- There was a remarkable improvement in the performance of calibrated equation. Moreover, the calibration approach improves the reliability and consistency of different evapotranspiration equation.

- The GPI is better to index ranking of equations as it takes into account the integrated approach of all the selected evaluation statistics.

- The ranking based on GPI of evaluated evapotranspiration models shows that the proposed model performed very well without calibration with GPI value of 5.02 and worst performance shown by Trabert.

- The ranking based on GPI of calibrated model reveals the fact that proposed model performed efficiently with the coefficient of determination up to 0.987 with GPI value of 2.85 and the worst performance shown by Meyer model

- Validation of calibrated equation shows that the proposed method was the most promising model and can be used as an alternative approach to Standard FAO56 Penman Monteith model under the limited climatic condition followed by Albrecht model.

- The results of this study could be used by the water management system, crop cultivators, crop advisors, researchers and students from universities and research centres. Moreover, it is beneficial for the decision maker in the vast field of agriculture, hydrology and environment.

Acknowledgments. The authors would like to acknowledge the Deanship of Scientific Research (King Khalid University, Ministry of Education, Kingdom of Saudi Arabia) for providing administrative and financial support (award number R.G.P.1./74/40). The authors of current work wish to thank Universiti Tecknologi Malaysia, Johor Bahru for their facilities and Lab support. We would also like to thank general authority of the meteorological department, Abha, Asir region, Saudi Arabia for providing the weather data.

Conflict of interests: The authors declare no conflict of interests. 


\section{REFERENCES}

[1] Abo-Ghobar, H. M., Mohammad, S. (1995): Evapotranspiration measurement by lysimeters in a desert climate. - Arab Gulf Journal of Scientific Research 13(1): 109-122.

[2] Albrecht, F. (1950): Die Methoden zur Bestimmung der Verdunstung der natürlichen Erdoberfläche. - Archiv für Meteorologie, Geophysik und Bioklimatologie, Serie B 2(12): $1-38$.

[3] Ali, M., Jamil, B. (2019): Estimating diffuse solar radiation in India: performance characterization of generalized single-input empirical models. - Urban Climate 27: 314350 .

[4] Ali, M. H., Shui, L. T. (2009): Potential evapotranspiration model for Muda irrigation project, Malaysia. - Water Resources Management 23(1): 57.

[5] Allen, R. G. (1996): Assessing integrity of weather data for reference evapotranspiration estimation. - J. Irrig. and Drain. Engrg., ASCE 122(2): 97-106.

[6] Allen, R. G., Pereira, L. S., Raes, D., Smith, M. (1998): Crop EvapotranspirationGuidelines for Computing Crop Water Requirements. - FAO Irrigation and Drainage Paper 56. FAO, Rome.

[7] Al-Omran, A. M., Al-Ghobari, H. M., Alazba, A. A. (2004): Determination of evapotranspiration of tomato and squash. - International Agricultural Engineering Journal 13(142): 27-36.

[8] Arnold, J. G., Allen, P. M. (1996): Estimating hydrologic budgets for three Illinois watersheds. - Journal of Hydrology 176(1-4): 57-77.

[9] Behar, O., Khellaf, A., Mohammedi, K. (2015): Comparison of solar radiation models and their validation under Algerian climate - the case of direct irradiance. - Energy Conversion and Management 98: 236-251.

[10] Bogawski, P., Bednorz, E. (2014): Comparison and validation of selected evapotranspiration models for conditions in Poland (Central Europe). - Water Resources Management 28(14): 5021-5038.

[11] Brockamp, B., Wenner, H. (1963): Verdunstungsmessungen auf den Steiner See bei Münster. - Dt Gewässerkundl Mitt 7: 149-154.

[12] Dalton, J. (1802): Experimental essays on the constitution of mixed gases; on the force of steam or vapor from water and other liquids in different temperatures, both in a Torricellian vacuum and in air; on evaporation and on the expansion of gases by heat. Memoirs of the Literary and Philosophical Society of Manchester 5(2): 535-602.

[13] Despotovic, M., Nedic, V., Despotovic, D., Cvetanovic, S. (2015): Review and statistical analysis of different global solar radiation sunshine models. - Renewable and Sustainable Energy Reviews 52: 1869-1880.

[14] Djaman, K., Balde, A. B., Sow, A., Muller, B., Irmak, S., N'Diaye, M. K., ... Saito, K. (2015): Evaluation of sixteen reference evapotranspiration methods under Sahelian conditions in the Senegal River Valley. - Journal of Hydrology: Regional Studies 3: 139159.

[15] ElNesr, M., Alazba, A., Abu-Zreig, M. (2010): Spatio-temporal variability of evapotranspiration over the Kingdom of Saudi Arabia. - Applied Engineering in Agriculture 26(5): 833-842.

[16] Estévez, J., García-Marín, A. P., Morábito, J. A., Cavagnaro, M. (2016): Quality assurance procedures for validating meteorological input variables of reference evapotranspiration in mendoza province (Argentina). - Agricultural Water Management 172: 96-109.

[17] Gueymard, C. A. (2014): A review of validation methodologies and statistical performance indicators for modeled solar radiation data: towards a better bankability of solar projects. - Renewable and Sustainable Energy Reviews 39: 1024-1034. 
[18] Helfrich, K. R., Adams, E. E., Godbey, A. L., Harleman, D. R. F. (1982): Evaluation of Models for Predicting Evaporative Water Loss in Cooling Impoundments. - Final Report (No. PB-82-229725). Energy Lab, Massachusetts Inst. of Tech., Cambridge, USA.

[19] ISLAM, S., ABDUllah, R. A. B., ALGAHTANI, A., IRSHAD, K., \& HIROL, H. (2019): PERFORMANCE OF VAPOUR PRESSURE MODELS IN THE COMPUTATION OF VAPOUR PRESSURE AND EVAPOTRANSPIRATION IN ABHA, ASIR REGION, SAUDI ARABIA. -APPLIED ECOLOGY AND ENVIRONMENTAL RESEARCH 17(4): 9691-9715

[20] Irmak, S., Irmak, A., Allen, R. G., Jones, J. W. (2003): Solar and net radiation-based equations to estimate reference evapotranspiration in humid climates. - Journal of Irrigation and Drainage Engineering 129(5): 336-347.

[21] Jabloun, M. D., Sahli, A. (2008): Evaluation of FAO-56 methodology for estimating reference evapotranspiration using limited climatic data: application to Tunisia. Agricultural Water Management 95(6): 707-715.

[22] Jensen, M. E. (1973): Consumptive Use of Water and Irrigation Water Requirements. ASCE, New York, pp. 215-215.

[23] Jensen, M. E. (1974): Consumptive Use of Water and Irrigation Water Requirements. ASCE, New York.

[24] Kiafar, H., Babazadeh, H., Marti, P., Kisi, O., Landeras, G., Karimi, S., Shiri, J. (2017): Evaluating the generalizability of GEP models for estimating reference evapotranspiration in distant humid and arid locations. - Theoretical and Applied Climatology 130(1-2): 377-389.

[25] Kisi, O., Zounemat-Kermani, M. (2014): Comparison of two different adaptive neurofuzzy inference systems in modelling daily reference evapotranspiration. - Water Resources Management 28(9): 2655-2675.

[26] Li, M. F., Tang, X. P., Wu, W., Liu, H. B. (2013): General models for estimating daily global solar radiation for different solar radiation zones in mainland China. - Energy Conversion and Management 70: 139-148.

[27] Mahringer, W. (1970: Verdunstungsstudien am Neusiedler See. - Archiv für Meteorologie, Geophysik und Bioklimatologie, Serie B 18(1): 1-20.

[28] Martins, D. S., Paredes, P., Raziei, T., Pires, C., Cadima, J., Pereira, L. S. (2017): Assessing reference evapotranspiration estimation from reanalysis weather products. An application to the Iberian Peninsula. - Int J Climatol 37(5): 2378-2397.

[29] Meyer, A. (1926): Über einige Zusammenhänge zwischen Klima und Boden in Europa. Doctoral Dissertation, ETH, Zurich.

[30] Mulaudzi, T. S., Maluta, N. E., Sankaran, V. (2015): Evaluation of the global solar irradiance in the Vhembe district of Limpopo Province, South Africa, using different theoretical modelsEvaluation of the global solar irradiance in the Vhembe district of Limpopo Province, South Africa, using different theoretical models. - Turkish Journal of Physics 39(3): 264-271.

[31] Penman, H. L. (1948): Natural evaporation from open water, bare soil and grass. Proceedings of the Royal Society of London. Series A. Mathematical and Physical Sciences 193(1032): 120-145.

[32] Popova, Z., Kercheva, M., Pereira, L. S. (2006): Validation of the FAO methodology for computing ETo with limited data. Application to South Bulgaria. - Irrigation and Drainage: The Journal of the International Commission on Irrigation and Drainage 55(2): 201-215.

[33] Rohwer, C. (1931): Evaporation from a Free Water Surface. - US Dept. of Agr. Tech. Bull. 271.

[34] Salih, A. M., Sendil, U. (1984): Evapotranspiration under extremely arid climates. Journal of Irrigation and Drainage Engineering 110(3): 289-303.

[35] Sentelhas, P. C., Gillespie, T. J., Santos, E. A. (2010): Evaluation of FAO PenmanMonteith and alternative methods for estimating reference evapotranspiration with 
missing data in Southern Ontario, Canada. - Agricultural Water Management 97(5): 635644.

[36] Singh, V. P., Xu, C. Y. (1997): Evaluation and generalization of 13 mass-transfer equations for determining free water evaporation. - Hydrological Processes 11(3): 311323.

[37] Stöckle, C. O., Kjelgaard, J., Bellocchi, G. (2004): Evaluation of estimated weather data for calculating Penman-Monteith reference crop evapotranspiration. - Irrigation Science 23(1): 39-46.

[38] Stone, R. J. (1993): Improved statistical procedure for the evaluation of solar radiation estimation models. - Solar Energy 51(4): 289-291.

[39] Tabari, H., Grismer, M. E., Trajkovic, S. (2013): Comparative analysis of 31 reference evapotranspiration methods under humid conditions. - Irrigation Science 31(2): 107-117.

[40] Trabert, W. (1896): Neue Beobachtungen über Verdampfungsgeschwindigkeiten. Meteorol. Z. 13: 261-263.

[41] Valipour, M. (2015a): Importance of solar radiation, temperature, relative humidity, and wind speed for calculation of reference evapotranspiration. - Archives of Agronomy and Soil Science 61(2): 239-255.

[42] Valipour, M. (2015b): Investigation of Valiantzas' evapotranspiration equation in Iran. Theoretical and Applied Climatology 121(1-2): 267-278.

[43] Widmoser, P. (2009): A discussion on and alternative to the Penman-Monteith equation. - Agricultural Water Management 96(4): 711-721.

[44] Willmott, C. J., Matsuura, K. (2005): Advantages of the mean absolute error (MAE) over the root mean square error (RMSE) in assessing average model performance. - Climate Research 30(1): 79-82.

[45] Winter, T. C., Rosenberry, D. O., Sturrock, A. M. (1995): Evaluation of 11 equations for determining evaporation for a small lake in the north central United States. - Water Resources Research 31(4): 983-993.

[46] WMO (1966): Measurement and estimation of evaporation and evapotranspiration. Tech. Pap. (CIMO-Rep) 83, Genf.

[47] Xu, C. Y., Singh, V. P. (2001): Evaluation and generalization of temperature-based methods for calculating evaporation. - Hydrological Processes 15(2): 305-319.

[48] Xu, J., Peng, S., Ding, J., Wei, Q., Yu, Y. (2013): Evaluation and calibration of simple methods for daily reference evapotranspiration estimation in humid East China. Archives of Agronomy and Soil Science 59(6): 845-858.

[49] Xystrakis, F., Matzarakis, A. (2010): Evaluation of 13 empirical reference potential evapotranspiration equations on the island of Crete in southern Greece. - Journal of Irrigation and Drainage Engineering 137(4): 211-222. 